\title{
1 Stability and load-displacement behaviour of axially cyclic loaded displacement piles in sands
}

2 S. Rimoy ${ }^{1}$, M. Silva ${ }^{2}$, R. Jardine ${ }^{3}$

$3{ }^{1}$ University of Dar es Salaam, Lecturer in the Department of Transportation and Geotechnical

4 Engineering, United Republic of Tanzania, rimoy@udsm.ac.tz

$5{ }^{2}$ Federico Santa Maria Technical University, Assistant Professor in the Department of Civil Engineering, 6 Chile, matias.silvai@usm.cl.

$7{ }^{3}$ Imperial College London, Professor in the Department of Civil and Environmental Engineering, United

8 Kingdom, r.jardine@imperial.ac.uk

\section{Abstract}

10 Uncertainties regarding the axial cyclic behaviour of piles driven in sands led to an extended 11 programme of calibration chamber instrumented pile experiments. Broad trends are identified and 12 interpreted with reference to normalised cyclic loading parameters $Q_{c y c l i c} / Q_{T}, Q_{m e a n} / Q_{T}$ and $N$. Cyclic damage is shown to be related to changes in the radial effective stress regime close to the shaft. While stable loading leads to little or no change as cycling continues in the sand masses' effective stress regime, high-level cyclic loading can affect stresses far out into the sand mass. The test systems' chamber-to-pile diameter ratio has a significant impact on outcomes. Piles installed in loose, fine, sand are far more susceptible to cyclic loading than in denser, coarser sand. Little or no change in pile stiffness was seen in tests that remained within the stable cyclic region, even over 10,000 or more cycles. Unstable tests lost their stiffness rapidly and metastable cases showed intermediate

20 behaviours. The permanent deflections developed under cycling depend on the combined influence

21 of $Q_{\text {cyclic }} / Q_{T}, Q_{\text {mean }} / Q_{T}$ and $N$. While model tests provide many valuable insights into the behaviour of

22 piles driven in sand, they are unable to capture some key features observed in the field.

\section{Background}

24 The ability to sustain cyclic loading can be critical to structures founded on piles, particularly in 25 offshore energy applications; see Jardine et al (2012) or Andersen et al (2013). However, relatively 26 little information exists to help guide designers, especially in sands. The French National Sollicitations

27 Cycliques sur Pieux (SOLCYP) programme described by Puech and Garnier (2017) aimed to address this 28 shortfall. Axial cyclic design methodologies were proposed for sands based on monotonic and cyclic 29 field tests on driven and bored piles, drawing on the one-way (OW) tension and two-way (TW) tension 30 and compression cyclic experiments conducted by Jardine and Standing (2012) on seven, 457mm 31 outside diameter, mostly $19 \mathrm{~m}$ long, open steel piles driven in medium-to-fine dense Dunkirk sand, in 
northern France. Relevant parallel studies at the same location include: (i) those by Jardine et al (2006)

33 and Carroll et al (2020) into how ageing affects the axial capacity of open steel driven piles and (ii) the

34 PISA project's multiple tests on driven steel monopiles subjected to monotonic and cyclic lateral

35 loading (see Byrne et al 2017; Zdravkovic et al 2020 and MacAdam et al 2020).

36 Field cyclic test outcomes

37 Thirteen cyclic axial tests conducted at Dunkirk led to the interactive stability diagram shown in Figure

381 which delineates how responses to regular cycling depend on the combination of mean pile head

39 load $\left(Q_{\text {mean }}\right)$ and cyclic amplitude $\left(Q_{\text {cyclic }}\right)$, relative to the tension shaft capacity $\left(Q_{T}\right)$, and number $(N)$ of

40 cycles.It categorises pile behaviour under cycling as being potentially:

41 - Stable (S), where pile head axial displacements accumulate very slowly over thousands of cycles

42 and there is no significant loss of shaft capacity,

43 - Unstable (US), where displacements accumulate relatively rapidly and shaft capacity falls to give 44 failure within 100 cycles, or

- $\quad$ Meta-Stable (MS), where displacements accumulate at moderate rates without stabilising. Capacity losses accrue that lead to failure after 100 s or 1000 s of cycles.

47 The normalised cyclic outcomes appeared broadly insensitive to the piles' ages after driving and prior 48 axial loading histories. Rimoy et al. (2013) analysed the piles' cyclic axial load-displacement and

49 stiffness responses, showing that stable cycling led to minimal displacement accumulation and no

50 stiffness loss. However, unstable cycling led to displacement drifts and stiffness reductions that

51 accelerated rapidly as failure was approached, while metastable cycling led to intermediate

52 behaviours. Rimoy et al (2013) illustrated how normalised displacement accumulations varied with

53 the normalised loading parameters through 3-D plots, as shown in Figure 2. Bored and cast in-situ

54 were tested cyclically nearby (at Loon Plage) in a similar sand profile proved to be far more sensitive

55 to load cycling. The stress relief and lack of pre-conditioning cycles implicit in their installation process

56 left them far less able than driven piles to sustain repetitive loading; Puech and Garnier (2017).

\section{Further research requirements and earlier model tests at Grenoble}

58 While the Dunkirk tests provide a uniquely valuable dataset, they could not consider how different

59 sand conditions might affect cyclic performance. It was impossible to measure soil contact stresses on

60 the driven piles' surfaces, or in the sand mass. Extending the tests to cover more than $\approx 1000$ cycles

61 was also unfeasible. Cyclic laboratory tests conducted on small model piles, under 1-g conditions, or

62 by multi-g centrifuge techniques (Guefrech et al. 2012, Blanc et al. 2015, Blanc \& Thorel 2016, Isorna 
63 et al. 2017) offer a potential means to address such gaps in knowledge, as reported from Chan and

64 Hanna (1980) onwards. However, the practical credibility of such experiments depends on the degree 65 to which they represent field conditions.

66 Jardine et al (2013a, b), Tsuha et al. (2012) and Rimoy et al (2015) reported experiments with $1 \mathrm{~m}$ long,

$6736 \mathrm{~mm}$ diameter model piles in the $1.20 \mathrm{~m}$ diameter, $1.50 \mathrm{~m}$ deep, fully pressurised Grenoble-INP

68 calibration chamber, aiming to study in greater detail the phenomena observed in the field. The

69 experiments were run under strictly controlled environmental conditions, with multiple miniature

70 sensors gauging the local stresses both on the pile shaft and in the dry sand employed: see Jardine et

71 al (2009) and Zhu et al (2009). Crucial differences between field and laboratory behaviour soon

72 became evident. Rimoy et al (2015) noted that the model piles did not display the same marked

73 growth of shaft capacities in the weeks and months that follow installation. Carroll et al (2020)

74 ascribed this to (i) physio-chemical conditions being different in the laboratory and (ii) potential scale

75 and geometrical effects that result from the finite thicknesses of zones of crushed sand grains formed

76 around the walls of open tubular steel piles. Nevertheless, the model tests offered new insights into

77 the effective stress conditions developed during installation, static load testing and under repetitive

78 loading (with up to 1000 cycles) in dense dry silica Fontainebleau NE34 sand.

\section{The extended Grenoble study}

80 This paper reports further model experiments conducted by Rimoy (2013) and Silva (2014) at Grenoble

81 with similar systems that explored the potential influences on cyclic behaviour of:

82 1) Different sands and initial sand states

83 2) Calibration chamber boundary conditions

84 3) Larger numbers of cycles and a wider range of loading regimes

85 4) Installation by driving as well as jacking

86 The experiments provided both new insights into displacement behaviour and an opportunity to re-

87 assess the relative advantages and disadvantages of field versus laboratory testing.

88 Model piles

89 The model test piles comprised either:

90 - Closed-ended, 36mm diameter (D) cone-tipped driven 'DT' piles equipped with axial load 91 cells, or

92 - The cone-tipped, stainless-steel, $36 \mathrm{~mm}$ diameter (D) Mini-Imperial College Pile (Mini-ICP)

93 shown in Figure 3, which records local shaft shear and radial stresses accurately through three

94 sets of Surface Stress Transducers (SSTs) as well as axial loads and temperatures. 
95 Careful consideration had to be given to the ratio between pile centreline surface roughnesses ( $\left.R_{c l a}\right)$

96 and diameter D, which affects the axial capacity of model piles markedly; see Jardine et al (2005) or

97 Carroll et al (2018). Adopting the typical $R_{c l a} \approx 10 \mu \mathrm{m}$ of industrial piles for small diameter model piles

98 would lead to the component of shaft resistance (equal to $\Delta \sigma^{\prime}{ }_{r d} \tan \delta$ ) that results from constrained

99 interface dilation dominating capacity. The model piles were therefore air-abraded to lower $R_{\text {cla }}$ values

100 of $3-4 \mu \mathrm{m}$ to reduce any unintended model scale effects. The pile tips had the same geometry as

101 standard $36 \mathrm{~mm}$ diameter CPT cones.

102 Calibration chamber testing arrangements

103 Each model pile was installed in a new $\approx 2.7$ tonnes mass of air-pluviated sand contained within the 104 test calibration chamber. Fontainebleau NE34 or GA39 sands were employed, whose index properties 105 are listed in Table 1. Detailed characterisation of NE34 has been reported by Yang et al (2010), 106 Aghakouchak (2015), Aghakouchak et al. (2015), Altuhafi et al (2018), Liu (2018), and others; the last 107 three references also considered Dunkirk sand, showing that it has similar mechanical behaviour to 108 NE34. GA39 also has broadly similar behaviour, despite its smaller grain size.

109 Rimoy (2013) and Silva (2014) describe the systems employed to measure local stresses and loads in 110 the sand masses while maintaining good long-term boundary stress and temperature controls.

111 Multiple miniature stress sensors were deployed, whose marked non-linear cell action interaction

112 effects were recognised and carefully calibrated, following Zhu et al. (2009). The sand masses could

113 be tested dry, or after near-saturation with water following $\mathrm{CO}_{2}$ replacement, employing initial density 114 indices $I_{D} \approx 40 \%$ and $70 \%$ for the GA39 and NE34 sands respectively. Vertical pressures of $150 \pm 5 \mathrm{kPa}$ 115 were maintained before pile installation, over extended ageing durations and during load testing.

116 The experimental chamber-to-pile diameter $\left(D_{\text {chamber }} / D\right)$ ratios was 33.3. Although much lower ratios 117 are frequently adopted, Salgado et al. (1998) argue that field conditions can only be matched in rigid 118 chambers if $D_{\text {chamber }} / D>100$. Check tests were therefore undertaken with a range of 'passive' and 119 'active' conditions (after Huang \& Hsu 2005):

120 - BC1 - Passive stress-controlled radial boundaries, with three depth-segmented water-filled 121 membranes held under constant applied pressure

122 - BC3 - Passive radial rigid-wall, as imposed by the steel chamber boundary - BC5 - Active radial boundaries that replicated 'field conditions' through three depthsegmented water-filled membranes which are isolated to measure the three boundary pressures during installation. The elevated pressures achieved at end of installation were held fixed throughout ageing to compensate for the effects of elastic strain energy stored beyond 
the limit of the calibration chamber wall in the field. The membranes could be isolated if required during static or cyclic testing.

129 Figure 4 presents the tip resistance profiles recorded during continuous monitoring of the jacked Mini-

130 ICPs into the sand masses contained in the calibration chamber. These traces, which are equivalent to

131 CPT qc profiles, show profiles that tend to a steady maximum equivalent qc $\approx 20 \mathrm{MPa}$ in NE34 sand,

132 while the finer GA39 sand profiles developed maxima of $\approx 10$ and $\approx 15 \mathrm{MPa}$ in tests ICP05 and ICP10

133 respectively.

134 Pile testing methods and programme

135 This paper reports 43 cyclic and 42 static tests conducted on 5 'DT' and 7 Mini-ICP piles. Table 2 outlines all the installations and loading sequences considered in this paper. Tests on the finer GA39

137 sand were conducted with a density index $I_{D} \approx 0.40$, while tests on the NE34 sand with an $I_{D} \approx 0.70$.

138 Mini-ICPs ICP04 to 11 were jacked to their final base depth of $980 \mathrm{~mm}$ in around 50 jack strokes, 139 applied at $2 \mathrm{~mm} / \mathrm{s}$, followed by full unloading at $0.01 \mathrm{~mm} / \mathrm{s}$ to zero pile head load, as in pile driving.

140 The driven piles were installed through a $3 \mathrm{~m}$ high aluminium tubular frame. A driving mechanism 141 released a $14.8 \mathrm{~kg}$ hammer, allowing it to fall through drop-heights that could be varied. The drop142 heights were progressively increased as the series progresses, from $\approx 800 \mathrm{~mm}$ for piles DT III and DTIV, 143 to more than $2 \mathrm{~m}$ for DTVI and DTVII. Rimoy (2015) gives further details of the earlier trial piles DTI and 144 DTII.

145 The static testing was conducted under displacement control at a wide range of ages after installation. 146 Rimoy (2013) shows that the jacked stainless-steel model piles' capacities were insensitive to age in 147 NE34 sand and generally fell close to those predicted with the CPT-based ICP-05 (Jardine et al 2005) 148 procedures. The latter give generally unbiased predictions for field pile tests, covering wide range of 149 pile sizes and sand states, conducted 10 to 30 days after driving; see Jardine et al (2006) and Yang et 150 al (2017). However, the laboratory model piles driven into NE34 sand gave considerably lower tension 151 capacities than expected by ICP-05 predictions, indicating that calibration chamber tests do not 152 reproduce field driving conditions in a fully representative manner. Mini-ICP piles jacked into loose 153 GA39 sand also gave lower than expected tension capacities; installation in loose sand masses appears 154 difficult to match in calibration chambers; Rimoy (2013).

155 Cyclic testing was achieved by imposing smooth sinusoidal load or displacement waveforms at the pile 156 head, as illustrated in Figure 5. Rates between 0.5 and 8.5 cycles per minute were employed which 157 spanned the typical median offshore foundation loading period of $\approx 10$ s (or 6 cycles per minute). Most 158 of the cyclic tests were conducted under load control, following the $Q_{\text {mean }} / Q_{T}$ and $Q_{\text {cyclic }} / Q_{T}$ parameters 159 in Table 2 and 3. The cyclic tests' codes signify: first their Test Series numeral, then an extension 
denoting the mode (One-Way or Two-Way), followed by the number of tests performed on the pile up to, and including, that stage. Reference shaft capacities $\left(Q_{T}\right)$ were measured through tension testing before most cyclic tests. Tension tests were adopted because they require smaller displacements (usually far less than $\mathrm{D} / 10$ ) than compression tests to reach peak resistance and are simpler to interpret. It is recognised that prior testing on any given pile affected the responses observed in any subsequent test and the reference static tension tests served to track the impact of prior experiments on axial shaft capacity. Tension loads are reported as having a negative sign. High level Two-Way cycling could not be sustained over many cycles without uncontrollable failure, so displacement control was employed for such cases. The loads sustained by the pile shafts varied as the pile shafts lost their resistance, leading to declining load paths in $Q_{\text {mean }} / Q_{T}$ and $Q_{\text {cyclic }} / Q_{T}$ space, as

170 noted in Tables 2 and 3.

\section{Axial cyclic loading tests results}

\section{Classification criteria}

173 The overall test outcomes are summarised through cyclic stability diagrams, which consider how the 174 number of cycles $N$ sustained before failure varied with loading conditions. Cyclic failure was defined 175 in terms of the accumulated cyclic displacements $a$ normalised by the pile diameter $D(\mathrm{~mm})$, and the 176 derivative $d(a / D) / d N$.

177 Stable (S) tests sustained at least 1000 cycles, displaced by less than 0.01D at rates less than or equal 178 to $3 \mathrm{D} \times 10^{-6} \mathrm{~mm} /$ cycle and showed no loss in operational static shaft capacity.

179 Unstable (US) tests accumulated total displacements greater than $0.1 \mathrm{D}$ at rates greater than $3 \mathrm{D} \times 10^{-}$ $180{ }^{4} \mathrm{~mm} /$ cycle over significant durations, showed significant shaft capacity degradation and generally 181 failed within 100 cycles.

182 Metastable (MS) tests showed intermediate displacements, displacement rates and modest shaft 183 capacity degradation that led to failure in hundreds of cycles. While small numbers of such cycles may 184 not affect capacity or serviceability, large numbers cannot be sustained safely.

\section{Outcomes for piles jacked into dry NE34 sand}

186 Figure $6 a$ considers the new tests on dry NE34 sand. These include a test taken to 7,000 cycles on 187 ICP04 (under BC3 conditions) as well tests on ICP07, ICP08 and ICP11 after their installation with BC5 188 conditions. The outcomes, categorised as Stable, Metastable or Unstable, manifest a similar pattern 189 to the Dunkirk field tests summarised in Figure 1. The displacement controlled ICP08 test provides an 190 interesting example in this plot. The $\mathrm{N}$ values annotated at five stages of the loading path followed by 
191 this experiment trace out how axial capacity degraded over several thousand cycles. After undergoing 192 immediate shaft failure during its first cycle, ICP08 showed sharp reductions in capacity and stiffness 193 as its load path migrated down to levels at which load-controlled tests had been fully stable. The pile 194 was mobilising less than $10 \%$ of its initial capacity when cycling ended after 20,002 cycles and a post195 cycling tension test proved that it has lost $\approx 70 \%$ of its initial shaft capacity.

\section{Impact of sand grain size and relative density}

197 Sand density and grain size effects were investigated next in installations ICP05 and ICP10, which 198 imposed $\mathrm{BC} 3$ and $\mathrm{BC} 5$ conditions respectively. While it had been intended to achieve a similar $\mathrm{I}_{\mathrm{D}}$ to 199 that of the NE34 ( $\approx 0.70)$ test with the finer GA39 by a modified air-pluviation procedure, this proved 200 difficult, and the final $I_{D}$ achieved was $\approx 0.40$. Tables 2 and 3 shows that the looser and finer sand 201 masses led to far less favourable monotonic and normalised cyclic capacities. The nine load-controlled 202 tests plotted in Figure 6c for GA39 sand show normalised boundaries that fall well below those 203 manifested by denser NE34 sand.

\section{Interface effective stress paths from Mini-ICP tests in dry sand}

205 The new cyclic loading tests undertaken in the ICP05 to 11 experiments revealed similar styles of 206 effective stress responses applied with: (i) a range of calibration chamber boundary conditions, (ii) wet 207 NE34 sand, (iii) finer, looser, dry GA39 sand, (iv) in many tests, after far larger numbers of cycles. Figure 2087 illustrates these trends with SST data recorded at three levels of the pile shafts in dry NE34 sand 209 tests employing BC5 conditions. Figure 7a) illustrates a stable test (ICP07-OW1) which confirms that 210 the trends identified by Tsuha et al (2012) are not affected significantly by changing the boundary 211 conditions: the local stress loops remain immobile and do not engage the interface shear criterion.

212 Figures $7 \mathrm{~b}$ ) and c) illustrate the impact of the unstable, extreme two-way applied conditions in the 213 earlier discussed ICP08 TW1 experiment, considering in Figure 7b) both the first 10 and the final 20 214 cycles of this 20,002 cycles experiment. As in Tsuha et al's (2012) tests, the +/- 0.5mm movements (or $215+/-2.8 \%$ of the pile diameter $\mathrm{D}$ ) imposed were sufficient to cause all points on the shaft to engage the 216 interface shear failure envelope, even though larger displacements (up to $D / 10$ ) would be required to 217 achieve static failure after dilation to 'critical states'; see Jardine et al (2013a, b). The latter test 218 indicated a higher interface shearing angle $\approx 30^{\circ}$, possibly reflecting an inadvertently rougher surface 219 texture with this pile.

220 Rimoy (2103) found more significant differences from Tsuha et al's (2012) patterns in his (dry) Mini221 ICP tests with the finer, loose, GA39 sand, which developed far lower axial resistances and radial shaft 222 shear stresses than were seen with NE34 sand under the same (150 kPa) vertical calibration chamber 
223 pressure. Figures $8 \mathrm{a}$ ) and 8b) present ICP05's interface stress paths, as measured at two shaft levels

224 in tests ICP05 OW1 and TW1 under BC3 conditions. While the OW1 experiments' $Q_{\text {cyclic }} / Q_{T}, Q_{\text {mean }} / Q_{T}$

225 coordinates plot in the denser NE34 sand's 'stable' region, the GA39 stress paths engaged the

226 interface shear envelope the start of cycling and showed marked $\sigma^{\prime}$ rs reductions and cyclic

227 displacement growth. Higher interface shear angles $\left(\delta \approx 34^{\circ}\right)$ applied because of the higher normalised

228 pile-soil roughness ratio $\mathrm{R} / \mathrm{d}_{50}$; as noted in ring-shear tests by Ho et al (2011). The next (TW1) cyclic

229 test on ICP-05 developed more open effective stress path loops and more significant stationary

230 effective radial stresses, $\sigma^{\prime}{ }_{r s}$ drift. Shaft capacity losses of $7 \%$ and $22 \%$ respectively were confirmed by

231 post-cyclic tension tests, confirming a metastable response. Further cyclic tests (TW2 and OW2) on

232 ICP05 led to metastable and unstable responses respectively, with further modest reductions in $\sigma_{r s}$

233 and shaft capacity. These experiments, and later tests on ICP10 (which was installed in loose GA39

234 under BC5 boundary conditions) confirmed the higher interface shear angles and provided more

235 information on the model piles' greater susceptibility to cyclic loading, in both absolute normalised

236 terms, when installed in the finer and looser GA39 sand.

\section{Piles installed in submerged NE34 sand}

238 Direct comparison between the dry sand model experiments and the Dunkirk field tests might be 239 questioned on several grounds, including the key difference that the field piles developed most of 240 their capacity below the water table. Experiment ICP06 was designed to test whether water influenced

241 the outcomes by installing a Mini-ICP, under BC3 conditions, in near-saturated NE34 sand. A 242 displacement-controlled, TW, test was then conducted, followed by a fully stable OW test to over 2431000 cycles, which raised the shaft capacity marginally, as listed in Table 2 . The normalised outcomes 244 of both tests are presented in Figure 6b, showing fully compatible trends to Figure 6a: submerging the 245 sand did not affect the normalised cyclic stability patterns.

246 Rimoy's (2015) investigation of how water affected behaviour identified again asymmetric 'butterfly-

247 wing' local interface stress path patterns over the first ten cycles of his displacement controlled (=/-

$2480.5 \mathrm{~mm}$ ) TW1 test on ICP06. As before, the paths were constrained by the $\delta=27^{\circ}$ interface shearing 249 angle, before progressing with gradually reducing rates of $\sigma_{r s}^{\prime}$ loss to greatly diminished final 250 conditions after 12,000 cycles. A post-cyclic tension test confirmed a $71 \%$ loss of shaft capacity, close 251 to that observed with dry sand in ICP08.

\section{Influence of installation method}

253 The influence of installation procedure was investigated further by driving closed ended $36 \mathrm{~mm}$ 254 diameter piles DTIII to DTVII in dry, $\mathrm{I}_{\mathrm{D}} \approx 0.70$, NE34 sand under BC1 and BC5 conditions. A total of 
255 twenty-one (OW and TW) cyclic loading tests were performed, as listed in Table 3, leading to the

256 results plotted in Figure 6d. The model driven piles' normalised unstable, metastable and stable

257 boundaries plot below those manifested by comparable cyclically jacked piles (Figure 6a and b) and

258 also the Dunkirk field test trends in Figure 1. Possible reasons for this discrepancy are discussed later.

259 Measurements were also made in BC5 tests of the pressures developed in the chamber's three,

260 vertically stacked, outer radial chamber membranes. The membranes were isolated during the TW1

261 test on ICP08 and Figure $9 b$ ) shows that an $\approx 10 \mathrm{kPa}$ reduction in $\sigma^{\prime}{ }_{r s}$ developed out at $r / R \approx 30$,

262 confirming that either larger chambers or active boundary conditions (such as the BC5 system) are

263 required to capture the field response in a fully representative manner.

264 Boundary pressure measurements made with BC5 conditions during installation showed increases

265 during jacked installation (when the membranes were isolated) that contrasted with radial pressures

266 falling sharply at the chamber wall during equivalent driven installations; see Figure 10a) and 10b).

267 The top membrane's vertical pressure also diminished by $\approx 30 \%$ by the end of driving. Balachowski

268 (1995) reports similar reductions lateral membrane pressures when an open-ended pile was driven

269 into a calibration chamber filled with very dense sand. Reduced-scale physical modelling of dynamic

270 pile installation presents considerable challenges because the driving energy that is free to radiate

271 away under field driving conditions may be reflected and conserved within confined test chambers in

272 an unrepresentative manner.

273 Cyclic stress variations in the sand-pile interface

274 The Mini-ICP piles' instrumentation allowed the cyclic local shear stress $\tau_{\mathrm{rz}}$ versus normal radial

275 effective stress $\sigma_{r}^{\prime}$ stress paths to be followed at the sand-pile interface, which was not possible with

276 the piles driven in the field or laboratory. It is also possible to follow the stress paths invoked within

277 the surrounding sand mass. Tsuha et al. (2012) reported on the paths followed at three levels on the

278 shaft in dry $\left(I_{D} \approx 0.70\right)$ NE34 sand under $B C 1$ and $B C 3$ conditions, showing that stable tests' stress paths

279 remained within an interface failure envelope, for which $\delta \approx 27^{\circ}$ in accordance with Yang et al's (2011)

280 ring-shear interface tests. As in the field, stable cycling led to either modest shaft capacity gains, or no

281 loss in tension resistance. However, unstable tests' effective stress paths engaged the $\delta \approx 27^{\circ}$

282 envelopes from an early stage and developed 'butterfly-wing' shaped paths that collapsed inwards

283 with each unloading stage and resembled those of sands undergoing undrained 'cyclic mobility' in

284 saturated triaxial or simple shear tests, even though the sand was dry. Marked losses in the stationary

285 (or mid-cycle) $\sigma_{r s}^{\prime}$ values developed as cycling progressed that led rapidly to failure. The metastable

286 tests' stress paths fell between these limits, with slower reductions in $\sigma^{\prime}{ }_{r}$ that led to shaft failure after

287100 s or 1000 s of cycles. Jardine (2020) ascribed these trends to the kinematic conditions applying at 
288 the pile shaft, which maintain near constant volume conditions even though the dry (or wet) sand can

289 drain freely. He also showed how this could be predicted from triaxial or Hollow Cylinder Apparatus

290 experiments that followed the protocols outlined by Aghakouchak et al (2015).

291 Cyclic stress variations in the sand mass

292 Tsuha et al (2012) and Jardine et al (2013 a, b) showed how the radial, circumferential and axial stress

293 measurements made within the sand mass could be combined with vertical shear stress distributions

294 inferred from the SST pile instruments to track the 4-dimensional $\left(\sigma_{z}^{\prime}, \sigma_{r}^{\prime}, \sigma_{\theta}^{\prime}\right.$ and $\left.\tau_{r z}\right)$ cylindrical stress

295 system within the sand mass during cyclic pile load tests. Stable tests led to local effective stress paths

296 that inevitably engaged and re-located the sand's elastic $\left(Y_{1}\right)$ kinematic yield surface (KYS) but

297 remained within its second $Y_{2}$ KYS, as defined by Jardine (1992), (2013). This system of KYSs was

298 identified and explored in cyclic laboratory tests on Dunkirk and NE34 sands by Kuwano (1999) and

299 Aghakouchak et al (2015). The radial $\sigma_{r}^{\prime}$ stress changes provoked within the surrounding sand mass by

300 severe two-way cycling are illustrated in Figure 8a) by measurements made at three normalised radial

301 distances $(r / R)$ from the pile axis at a normalised level $h / R=39.2$ vertically above the tip in test TW1

302 on ICP08. While the pile shaft experiences large $(\approx 130 \mathrm{kPa})$ final losses in $\sigma_{\mathrm{rs}}^{\prime}$, significant $(\approx 50 \mathrm{kPa})$

303 reductions extended out to 2 to 8 radii from the axis.

304 Cyclic stiffness

305 Cyclic stiffnesses, $k=\left(Q_{\max }-Q_{\min }\right) / d_{c y c l i c}$, were defined as outlined in Figure 11 . The loading and 306 unloading values $k_{l}$ and $k_{u}$ generally converged but could show differences when 'viscous' effects 307 delayed the strain peaks and significant strains accumulated during each cycle in unstable tests. Tables 3082 and 3 lists the stiffness measured over the first cycle of cycling $k_{1, N=1}$. The loose GA39 sand tests 309 developed similar stiffnesses than the NE34 cases, within which stiffnesses generally reduced as $Q_{T}$ 310 fell (due to prior testing) and/or the imposed normalised loading levels rose. Figure 11a) displays the 311 latter trends for GA39 and NE34 sand cases by plotting non-dimensional stiffness $k_{1}, N=1$ multiplied by 312 diameter $D$ and divided by $Q_{T}$ against $Q_{c y c} / Q_{T}$ for jacked pile tests, differentiating cases with $0 \leq$ $313 Q_{\text {mean }} / Q_{T}<0.3$ from those with $0.3 \leq Q_{\text {mean }} / Q_{T} \leq 0.6$, while Figure $11 b$ ) shows the equivalent for driven 314 piles. Jacked pile tests showed similar non-dimensional stiffness as Dunkirk field tests at significantly 315 lower levels of normalised cyclic loading. On the contrary, driven piles tests present a degradation of $316 k_{1, N=1}$ as $Q_{c y c} / Q_{T}$ progresses for similar cyclic amplitudes as the jacked piles.

317 Figure 13 goes onto show how loading stiffnesses (and therefore cyclic displacements) remained 318 practically constant up to 10,000 cycles in the stable ICP04-OW1, ICP06-OW1, ICP07-OW1, ICP07-TW1 319 and ICP11-OW1 tests by plotting $\mathrm{k}_{\mathrm{l}} / \mathrm{k}_{\mathrm{l}, \mathrm{N}=1}$ against logarithm of $\mathrm{N}$. The equivalent data from the 
metastable tests ICP04-TW1, ICP04-OW2, ICP05-OW2, ICP05-TW1, ICP05-TW2, ICP10-OW4, ICP10-

321 TW2 and ICP11-OW2 are also shown. Most of the latter also manifested nearly constant stiffness.

322 However, in some cases, such as ICP04-TW1, stiffness degraded by up to $85 \%$ as failure approached.

323 The corresponding unstable cyclic loading tests stiffness trends are illustrated in Figure 14. Test ICP05-

324 OW2, ICP11-OW3 and ICP11-TW1 survived to just 74, 61 and 25 cycles respectively and showed cyclic

325 stiffness degrading after just 10 to 30 cycles. Figures 15 and 16 show how the driven piles' normalised

326 stiffnesses varied with number of cycles, giving broadly similar trends to the jacked piles. Overall, no

327 clear difference could be seen between the stiffness degradation trends developed under $\mathrm{BC} 3$ or $\mathrm{BC} 5$

328 conditions in wet-or-dry, loose-or-dense sand masses, by jacked or driven piles.

329 Permanent accumulated cyclic displacements

330 The permanent cyclic pile-head displacements accumulated during load-controlled cycling are shown

331 in Figure 17 to 19. Naturally, the displacement-controlled tests did not develop permanent

332 displacements. The segmented reference lines correspond to the stability criteria discussed earlier,

333 which are broadly consistent with the Dunkirk field tests analysed by Rimoy et al. (2013) although

334 some differences exist in the rates at which the cyclic displacements (divided here by diameter D)

335 grew as cyclic failure approached under metastable or unstable conditions. Stable cyclic tests showed

336 almost negligible displacement accumulation rates, independent of the installation method, sand type

337 and density indices.

338 Figure 2 illustrated the relationships found by Rimoy et al (2013) between the $Q_{c y c} / Q_{T}, Q_{m e a n} / Q_{T}$ and $N$ 339 conditions at which permanent displacements reached 2\%D in the full-scale Dunkirk tests. Figures 19 340 provide a comparison between Dunkirk results and the equivalent surfaces for tests on dry NE34 for 341 displacement levels 0.2D. While reduced-scale model piles showed similar trends to the Dunkirk field 342 test, they are unable to capture pile response at high levels of cyclic amplitude. Figure $20 \mathrm{~b}$ and 20c 343 shows that model piles reached equivalent normalised displacement levels under lower normalised 344 cyclic amplitudes, confirming their narrower metastable zone and smaller stable region, as identified 345 earlier in Figure 6. Rimoy (2013) and Silva (2014) give further details of, and discussion on, the model 346 piles' permanent displacement trends.

\section{Discussion}

348 The studies described in this paper explored first how cyclic stability diagrams could be constructed 349 from model tests. The tests examined aspects that could not be varied easily in the field, including 350 sand state, grading and large numbers of load cycles, through both displacement and load-controlled 351 arrangements. The experiments also investigated whether the stability outcomes vary between cases 
where the sand mass is dry or saturated with water, as well as the influence of model test boundary conditions. The multiple stress sensors deployed in the experiments provided new insights into the

354 local conditions developed on the surfaces of jacked Mini-ICP piles, within the surrounding soil mass 355 and on the calibration chamber boundaries during installation and cyclic testing. These observations 356 are valuable to the formulation of representative degradation laws for incorporation into FEM or local 357 (t-z) soil-pile cyclic analyses. Finally, the tests provided information on the highly non-linear stiffness 358 response and permanent displacement growth trends of the model piles under cyclic loading. These 359 outcomes are valuable, given the very sparse evidence that has been reported through field cyclic 360 loading experiments on piles driven in sands.

361 Designers of foundations intended to carry significant levels of cyclic loading require guidance on how 362 to consider repetitive loading cases safely and economically. Jardine et al (2012) and Puech and 363 Garnier (2016) summarised how this might be achieved through the routes incorporated in the 364 'SOLCYP' scheme shown in Figure 20. Reliable cyclic stability diagrams, such as Figure 1, can aid both 365 preliminary screening studies and quantitative global assessments; Jardine and Standing (2012). Such 366 procedures have applied in offshore projects reported by Merritt et al (2012) and Argiolas and Jardine 367 (2017). Figure 20 also identifies pathways for generating cyclic stability diagrams through site-specific 368 cyclic element testing, which may follow specific protocols (Aghakouchak et al 2015, or Jardine 2020), 369 as applied by Rattley et al (2017). Cyclic element testing can also inform or calibrate numerical 370 analyses that employ FEM or local (t-z) soil-pile cyclic tools, such as those reported by Atkins (2000).

\section{Potential differences between model pile outcomes and field behaviour}

372 However, it is crucial to consider how well the model piles represent field behaviour. The axial 373 capacities developed by piles jacked into NE34 sand appeared compatible with design rules that match 374 the field test capacities of open and closed ended piles in a wide range of relative densities, as 375 measured at moderate ages (around 10 days) after driving, although the degree of fit varies with the 376 calibration chamber boundary conditions; see Rimoy (2013).

377 Despite multiple variations being made in boundary conditions, sand states, installation procedures,

378 as well as cycles in the external calibration chamber pressures the jacked and driven model tests could 379 not replicate the marked set up trends reported from the Dunkirk field tests; Rimoy et al (2015). Model 380 tests cannot yet capture all aspects of the relevant physical processes and it is vital that attempts to 381 predict field pile behaviour through 1-g or centrifuge tests must recognise potential uncertainties 382 relating to test systems, such as the potential to conserve pile driving energy in an unrepresentative 383 manner, overly close boundaries, and scaling relationships that may not capture all of the physio384 chemical conditions that apply in the field. Model tests provide many valuable insights, but they do 
385 not obviate the need for high quality and comprehensive field testing as described by Karlsrud et al 386 (2014), Byrne et al (2017) or Carroll et al (2020).

387 Nevertheless, the NE34 sand model test results match the field findings when normalised by the 388 current pile tension capacities, $\mathrm{Q}_{\mathrm{T}}$. The experiments also provide clear evidence that water has little 389 independent impact on the normalised cyclic loading outcomes. They proved too that finer sands 390 develop higher $\delta$ angles and indicated that piles installed in loose sands are likely to have both lower 391 cyclic stiffness and be particularly susceptible to cyclic loading, even in normalised terms.

\section{Conclusions}

393 This paper reviewed current uncertainties regarding the axial cyclic behaviour of piles driven in sands, 394 referring to field tests before reporting and interpreting an extended programme of 43 , mostly heavily 395 instrumented, calibration chamber cyclic model pile tests supported by multiple static tests. The 396 programme was designed to explore the potential influences of (i) initial conditions in the sand, (ii) 397 large numbers of cycles and a wide range of loading regimes, (iii) calibration chamber boundary 398 conditions and (iv) pile installation by both driving and jacking. The experiments contribute towards 399 developing design guidance for cyclic axial loading cases and lead towards ten main conclusions:

400 1. Wet and dry sands placed at the same density indices follow the broadly same trends under 401 regular cyclic loading when the outcomes are considered in terms of the normalised cyclic loading 402 parameters $Q_{\text {cyclic }} / Q_{T}, Q_{\text {mean }} / Q_{T}$ and $N$.

403 2. Little or no change in cyclic stiffness occurs when loading remains within a well-defined stable 404 region, even over 10,000 or more cycles. In contrast, unstable tests lose stiffness rapidly and fail dramatically after less than 100 cycles. Metastable tests show intermediate responses that

407 3. Cyclic damage occurs due to reductions in the radial effective stresses acting on the shaft and 408 failure is controlled by interface failure angles that can be predicted by ring-shear laboratory 409 tests.

410 4. Stable loading leads to little or no change in the sand masses' effective stress regime as cycling continues, but the effects of high-level cyclic loading extend out into the surrounding sand mass.

4125 . The chamber-to-pile diameter ratio of 33 employed in the present tests led to significant radial stress variations at the chamber wall, whose impact could be reduced by adopting 'active' BC5 chamber boundary conditions. Model tests involving closer boundaries are inevitably less representative of field behaviour. 
416 6. The outcomes from cyclic tests undertaken with a range of conditions could be synthesised, and rational comparisons made between test Series', by employing the normalised loading parameters.

419 7. The jacked Mini-ICP calibration chamber tests in NE34 sand led to broadly similar normalised cyclic stability, stiffness and permanent displacement trends to full-scale field tests (conducted at various ages after driving) in Dunkirk sand, which has similar grain sizes, mechanical properties and in-situ $I_{D}$ levels to the main model test sand.

423 8. The calibration chamber tests confirm how the permanent deflections and stiffnesses developed under cycling depend on the loading parameters $Q_{c y c l i c} / Q_{T}, Q_{\text {mean }} / Q_{T}$ and $N$.

425 9. However, the model experiments were unable to capture reliably some of the key features observed in the field, including shaft capacity growth over time, the impact of driven rather than jacked installation and potentially the impact of low relative density sand layers. These outcomes may be unintended consequences of the model pile testing arrangements.

429 10. While model tests provide many valuable insights into the cyclic behaviour of piles driven in sand, they do not obviate the need for comprehensive, high-quality, field testing.

\section{Acknowledgements}

433 The authors gratefully acknowledge the sponsorship and provided by the Commonwealth Scholarship, 434 BECAS Chile, Engineering and Physical Sciences Research Council (EPSRC), Centre National de la 435 Recherche Scientifique (CNRS), the Health and Safety Executive (HSE), Shell (UK) and Total France. 436 They also wish to thank their many current and former colleagues at Imperial College and INGP

437 Grenoble as well as Cambridge In-situ for their contributions to the research described. They also 438 acknowledge the late Professor Pierre Foray ${ }^{\dagger}$ at Laboratoire 3SR in Grenoble for his contribution, 439 support, and legacy in offshore geotechnics.

\section{References}

441 Aghakouchak, A. (2015). Advanced laboratory studies to explore the axial cyclic behaviour of driven 442 piles. Doctoral dissertation, Imperial College London.

443 Aghakouchak, A., Sim, W. W., \& Jardine, R. J. (2015). Stress-path laboratory tests to characterise the 444 cyclic behaviour of piles driven in sands. Soils and Foundations, 55(5), 917-928. 445 https://doi.org/10.1016/j.sandf.2015.08.001 
Altuhafi, F., Jardine, R.J., Georgiannou, V.N., and Sim, W. (2018). Effects of particle breakage and stress

447 reversal on the behaviour of sand around displacement piles. Geotechnique. Vol: 68, p. 546-555. https://doi.org/10.1680/jgeot.17.P.117

449 Andersen, K. H., Puech, A. A., \& Jardine, R. J. (2013, September). Cyclic resistant geotechnical design 450 and parameter selection for offshore engineering and other applications. In Proceedings of the TC-

451209 Workshop, Design for Cyclic Loading: Piles and Other Foundations, Paris. Presses des Ponts (pp. 452 9-44).

453 Argiolas, R., \& Jardine, R. (2017). An Integrated Pile Foundation Reassessment to Support Life 454 Extension and New Build Activities for a Mature North Sea Oil Field Project. Proceeding 8th 455 International Conference on Offshore Site Investigations and Geotechnics, pp. 695-702.

456 Atkins Consultants Ltd (2000). "Cyclic degradation of offshore piles". Offshore Technology Report 457 2000/013 for the Health and Safety Executive.

458 Balachowski, L. (1995). Différents aspects de la modélisation physique du comportement des pieux: 459 Chambre d'Etalonnage et Centrifugeuse (Doctoral dissertation, Grenoble INPG).

460 Blanc, M., Thorel, L., Isorna, R., Dano, C., Kotronis, P., Maxime, P. (2015). Centrifuge investigation of 461 the axial cyclic behaviour of a single pile used for the foundation of a jacket type offshore wind turbine. 462 3rd International Symposium on Frontiers in Offshore Geotechnics (ISFOG), Jun 2015, pp.521-526.

463 Blanc, M., \& Thorel, L. (2016). Effects of cyclic axial loading sequences on piles in sand. Géotechnique 464 Letters, 6(2), 163-167. https://doi.org/10.1680/jgele.15.00155

465 Byrne, B.W., McAdam, R.A., Burd, H.J., Houlsby, G.T., Martin, C.M., Beuckelaers, W.J.A.P., Zdravković, 466 L., Taborda, D.M.G., Potts, D.M., Jardine, R.J., Ushev, E., Liu, T., Abadias, D., Gavin, K., Igoe, D., Doherty, 467 P., Skov Gretlund, J., Pacheco Andrade, M., Muir Wood, A., Schroeder, F.C., Turner, S. and Plummer, 468 M.A.L. (2017). PISA: New design method for offshore wind turbine monopiles. Proceeding 8th 469 International Conference on Offshore Site Investigations and Geotechnics. Keynote Paper.

470 Carroll, R., Carotenuto, P., Dano, C., Salama, I., Silva, M., Rimoy, S., Gavin, K., Jardine, R (2019). Field 471 experiments at three sites to investigate the effects of age on steel piles driven in sand. Géotechnique, 472 70(6), 469-489. https://doi.org/10.1680/jgeot.17.p.185

473 Chan, S. F., \& Hanna, T. H. (1980). Repeated loading on single piles in sand. Journal of Geotechnical 474 and Geoenvironmental Engineering, 106(2), 171-188.

475 Chow, F.C. (1997). Investigations into displacement pile behaviour for offshore foundations. PhD 476 Thesis, Imperial College, London. 
477 Guefrech, A., Rault, G., Chenaf, N., Thorel, L., Garnier, J., \& Puech, A. (2012, January). Stability of cast 478 in place piles in sand under axial cyclic loading. Proceeding 7th International Conference Offshore Site 479 Investigation and Geotechnics, SUT London, pp 329-334.

480 Hampson, K., Evans, T.G., Jardine, R.J., Moran, P., Mackenzie B.\& Rattley, M.J. (2017). BP Clair Ridge: 481 Independent foundation assurance for the capacity of driven piles in very hard soils. Proceeding 8th 482 International Conference on Offshore Site Investigations and Geotechnics, SUT London. Vol. 2, pp. 483 1299-1306. https://doi.org/10.3723/OSIG17.1299

484 Ho, Y.K., Jardine, R.J and Anh-Minh, N. (2011). Large displacement interface shear between steel and 485 granular media. Géotechnique, Vol 61, No. 3, pp 221-234. https://doi.org/10.1680/geot.8.P.086

486 Huang, A. B., \& Hsu, H. H. (2005). Cone penetration tests under simulated field conditions. 487 Géotechnique, 55(5), 345-354. https://doi.org/10.1680/geot.2005.55.5.345

488 Isorna, R., Blanc, M., Thorel, L., Kotronis, P., Dano, C., \& Philippe, M. (2017). Axial behaviour of jacket 489 piles for offshore wind turbines. International Journal of Physical Modelling in Geotechnics, 17(4), 229490 245. https://doi.org/10.1680/jphmg.15.00044

491 Jardine, R. J. (1992). Some observations on the kinematic nature of soil stiffness. Soils and foundations, 492 32(2), 111-124. https://doi.org/10.3208/sandf1972.32.2_111

493 Jardine, R. J., Standing, J. R., and Chow, F. C. (2006). Some observations of the effects of time on the 494 capacity of piles driven in sand. Géotechnique, 56(4): 227-244. 495 https://doi.org/10.1680/geot.2006.56.4.227

496 Jardine, R. J., \& Standing, J. (2012). Field axial cyclic loading experiments on piles driven in sand. Soils 497 and Foundations, 52(4), 723-736. https://doi.org/10.1016/j.sandf.2012.07.012

498 Jardine, R.J., Andersen, K. and Puech, A. (2012). Cyclic loading of offshore piles: potential effects and 499 practical design. Keynote Paper. Proc 7th Int. Conf. on Offshore Site Investigations and Geotechnics, 500 SUT London, pp 59-100.

501 Jardine, R. J., Zhu, B. T., Foray, P., \& Yang, Z. X. (2013a). Measurement of stresses around closed-ended 502 displacement piles in sand. Géotechnique, 63(1), 1-17. https://doi.org/10.1680/geot.9.P.137

503 Jardine, R., Zhu, B., Foray, P., \& Yang, Z. (2013b). Interpretation of stress measurements made around 504 closed-ended displacement piles in sand. Géotechnique, 63(8), 613-627. 505 https://doi.org/10.1680/geot.9.P.138 
506 Jardine, R.J. (2020). Geotechnics, Energy and Climate Change. 56th Rankine Lecture, Géotechnique.

50770 (1), pp. 3-59. https://www.icevirtuallibrary.com/doi/full/10.1680/jgeot.18.RL.001

508 Karlsrud K., Nadim F. \& Haugen T. (1985). Piles in clay under cyclic axial loading field test and 509 computational modelling. Proceedings of the 3rd International Conference on Numerical Methods in 510 Offshore Piling, Nantes, France, pp. 165-190.

511 Karlsrud, K., Jensen, T. G., Lied, E. K. W., Nowacki, F., \& Simonsen, A. S. (2014, May). Significant ageing 512 effects for axially loaded piles in sand and clay verified by new field load tests. In Offshore Technology 513 Conference. Offshore Technology Conference.

514 Liu, T. F. (2018). Advanced laboratory testing for offshore pile foundations under monotonic and cyclic 515 loading. Doctoral dissertation, Imperial College London.

516 McAdam, R.A., Byrne, B.W., Houlsby, G.T., Beuckelaers, W.J.A.P., Burd, H.J., Gavin, K.G., Igoe, D.J.P., 517 Jardine, R.J., Martin, C.M., Muir Wood, A., Potts, D.M., Skov Gretlund, J., Taborda, D.M.G. and 518 Zdravković, L. (2020). Monotonic laterally loaded pile testing in a dense marine sand at Dunkirk. 519 Géotechnique, 70(11), 986-998. https://doi.org/10.1680/jgeot.18.PISA.004

520 Merritt A.S., Schroeder F.C., Jardine R.J., Stuyts B., Cathie D. \& Cleverly D. 2012. Development of pile 521 design methodology for an offshore wind farm in the North Sea. Proceedings of the SUT 7th 522 International Conference on Offshore Site Investigation and Geotechnics, London, UK, pp. 439 - 447.

523 Poulos, H. G. (1988). Cyclic stability diagram for axially loaded piles. Journal of geotechnical 524 engineering, 114(8), 877-895. https://doi.org/10.1061/(ASCE)0733-9410(1988)114:8(877)

525 Puech, A., \& Garnier, J. (Eds.). (2017). Design of Piles Under Cyclic Loading: SOLCYP Recommendations. 526 John Wiley \& Sons.

527 Rattley, M.J., Costa, L., Jardine, R.J. and Cleverly, W. (2017). Laboratory test predictions of the cyclic 528 axial resistance of a pile driven in North Sea soils. Proc 8th Int. Conf. on Offshore Site Investigations 529 and Geotechnics, SUT London. SUT London. Vol. 2, p. 636-643. https://doi.org/10.3723/OSIG17.636

530 Rimoy, S. (2013). Ageing and axial cyclic loading studies of displacement piles in sands. Doctoral 531 dissertation, Imperial College London. https://core.ac.uk/download/pdf/17295009.pdf

532 Rimoy, S. P., Jardine, R. J., \& Standing, J. R. (2013). Displacement response to axial cycling of piles 533 driven in sand. Proceedings of the ICE - Geotechnical Engineering, 166(2), 131-146. 534 https://doi.org/10.1680/geng.12.00052 
535 Rimoy, S., Silva, M., Jardine, R., Foray, P., Yang, Z., Zhu, B. \& Tsuha, C. (2015). Field and model 536 investigations into the influence of age on axial capacity of displacement piles in silica sands, 537 Géotechnique 65 (7); pp 576 -589. https://doi.org/10.1680/geot.14.P.112

538 Salgado, R., Mitchell, J. K., \& Jamiolkowski, M. (1998). Calibration chamber size effects on penetration 539 resistance in sand. Journal of Geotechnical and Geoenvironmental Engineering, 124(9), 878-888. 540 https://doi.org/10.1061/(ASCE)1090-0241(1998)124:9(878)

541 Silva, M (2014). Experimental study of ageing and axial cyclic loading effect on shaft friction along 542 driven piles in sand. Doctoral dissertation, Université de Grenoble. https://tel.archives-ouvertes.fr/tel$543 \quad 01204765$

544 Tsuha, C., Foray, P., Jardine, R., Z.X., Y., Silva, M., \& Rimoy, S. (2012). Behaviour of displacement piles 545 in sand under cyclic axial loading. Soils and Foundations, 52(3), 393-410. 546 https://doi.org/10.1016/j.sandf.2012.05.002

547 Yang, Z. X., Jardine, R. J., Zhu, B. T., Foray, P., \& Tsuha, C. H. C. (2010). Sand grain crushing and interface 548 shearing during displacement pile installation in sand. Géotechnique, 60(6), 469-482. 549 https://doi.org/10.1139/cgj-2015-0518

550 Yang, Z. X., Guo, W.B., Jardine, R. J. and Chow, F. C. (2017). Design method reliability assessment from 551 an extended database of axial load tests on piles driven in sand. Canadian Geotechnical Journal 54(1), 552 59-74. https://doi.org/10.1139/cgj-2015-0518

553 Zdravković, L., Jardine, R.J., Taborda D.M.G., Abadias, D., Burd, H.J., Byrne, B.W., Gavin, K.G., Houlsby, 554 G.T., Igoe, D.J.P., Liu, T, Martin, C.M., McAdam, R.A., Muir Wood, A., Potts, D.M., Skov Gretlund, J. and 555 Ushev, E. (2020). Ground characterisation for PISA pile testing and analysis. Géotechnique, 70(11), 556 945-960. https://doi.org/10.1680/jgeot.18.PISA.001

557 Zhu, B., Jardine, R., \& Foray, P. (2009). The Use of Miniature Soil Stress Measuring Cells in Laboratory 558 Applications Involving Stress Reversals. Soils and Foundations, 49(5), 675-688. 559 https://doi.org/10.3208/sandf.49.675 


\section{$\underline{\text { Tables }}$}

\begin{tabular}{c|c|c|c|c|c|c|c|c|c}
\hline Sand & Grain shape & $\begin{array}{c}\mathrm{SiO}_{2} \\
(\%)\end{array}$ & $\mathrm{G}_{\mathrm{s}}$ & $\begin{array}{c}\mathrm{d}_{10} \\
(\mathrm{~mm})\end{array}$ & $\begin{array}{c}\mathrm{d}_{50} \\
(\mathrm{~mm})\end{array}$ & $\begin{array}{c}\mathrm{d}_{60} \\
(\mathrm{~mm})\end{array}$ & $\mathrm{C}_{\mathrm{u}}$ & $\mathrm{e}_{\max }$ & $\mathrm{e}_{\min }$ \\
\hline NE34 & Sub-angular, sub-rounded & 99.70 & 2.65 & 0.150 & 0.210 & 0.230 & 1.53 & 0.90 & 0.51 \\
\hline GA39 & Sub-angular, sub-rounded & 98.60 & 2.65 & 0.100 & 0.127 & 0.132 & 1.32 & 1.01 & 0.56 \\
\hline
\end{tabular}

Table 1: Index properties of NE34 Fontainebleau and GA39 Nemours sand 


\begin{tabular}{|c|c|c|c|c|c|c|c|c|c|c|c|}
\hline No. & $\begin{array}{c}\text { Test } \\
\text { Series }^{1,2,3}\end{array}$ & $\begin{array}{l}\text { Test } \\
\text { code }\end{array}$ & $\begin{array}{c}\text { Jack load } \\
(k N)\end{array}$ & $\begin{array}{c}\mathrm{N} \\
\text { cycles }\end{array}$ & $\begin{array}{c}\text { Rate } \\
\text { (N/min) }\end{array}$ & $\begin{array}{c}\text { Referential } \\
\qquad \mathbf{Q}_{\mathrm{T}}(\mathrm{kN})\end{array}$ & $\begin{array}{c}\mathbf{Q}_{\text {cyclicl }} \\
\mathbf{Q}_{\mathbf{T}}\end{array}$ & $\begin{array}{c}\mathbf{Q}_{\text {mean }} / \\
\mathbf{Q}_{\mathbf{T}}\end{array}$ & Description & $\begin{array}{c}\text { Post cycling } \\
\text { tensile capacity } \\
(\mathrm{kN})\end{array}$ & $\begin{array}{c}k_{\mathrm{l}, \mathrm{N}=1} \\
(\mathrm{kN} / \mathrm{mm})\end{array}$ \\
\hline \multicolumn{12}{|c|}{ Dry NE34 sand with BC3 boundary condition and density indices $I_{D} \approx 70 \%$} \\
\hline 1 & \multirow{3}{*}{ ICP04 } & OW1 & $-3.5-0$ & 7000 & 0.5 & -11.11 & 0.15 & 0.15 & Stable & -13.22 & 59.47 \\
\hline 2 & & TW1 & $-4.0-4.0$ & $600\left(N_{f}=580\right)$ & 3.0 & -13.22 & 0.23 & 0.06 & Meta-stable & -5.39 & 38.50 \\
\hline 3 & & OW2 & $-4.6--2.3$ & 50 & 6.0 & -5.39 & 0.21 & 0.63 & Meta-stable & -6.00 & 31.91 \\
\hline \multicolumn{12}{|c|}{ Wet NE34 sand with BC3 boundary condition and density indices $I_{D} \approx 70 \%$} \\
\hline 4 & \multirow{2}{*}{ ICP06 } & TW1 & Varies $^{2}$ & 12022 & $\sim 3.0$ & -15.49 & Varies & Varies & Unstable & -4.45 & -- \\
\hline 5 & & OW1 & $-1.0-0$ & 1000 & 8.5 & -4.45 & 0.11 & 0.11 & Stable & -4.69 & 64.12 \\
\hline \multicolumn{12}{|c|}{ Dry NE34 sand with BC5 boundary condition and density indices $I_{D} \approx 70 \%$} \\
\hline 6 & \multirow{2}{*}{ ICP07 } & OW1 & $-7.2--4.8$ & 4040 & 2.5 & -13.16 & 0.09 & 0.46 & Stable & $\begin{array}{l}-13.76 \\
\end{array}$ & 103.79 \\
\hline 7 & & TW1 & $-1.2-1.2$ & 4760 & 2.5 & -13.76 & 0.07 & 0.02 & Stable & -13.68 & 124.93 \\
\hline 8 & ICP08 & TW1 & Varies $^{2}$ & 20002 & $\sim 4.0$ & -11.50 & Varies & Varies & Unstable & -3.47 & -- \\
\hline 9 & \multirow{4}{*}{ ICP11 } & OW1 & $-6.47--2.58$ & 2500 & 2.15 & -13.19 & 0.14 & 0.34 & Stable & -15.97 & 67.07 \\
\hline 10 & & OW2 & $-8.73--2.32$ & $1163\left(N_{f}=1163\right)$ & 1.78 & -15.97 & 0.20 & 0.34 & Metastable & -15.17 & 67.35 \\
\hline 11 & & OW3 & $-10.5--1.59$ & $61\left(\mathrm{~N}_{\mathrm{f}}=61\right)$ & 0.61 & -15.17 & 0.29 & 0.40 & Unstable & -13.56 & 56.59 \\
\hline 12 & & TW1 & $-8.11-2.65$ & $25\left(N_{f}=25\right)$ & 1.19 & -13.56 & 0.39 & 0.21 & Unstable & -12.91 & 37.77 \\
\hline \multicolumn{12}{|c|}{ Dry GA39 sand with BC3 boundary condition and density indices $I_{D} \approx 40 \%$} \\
\hline 13 & \multirow{4}{*}{ ICP05 } & OW1 & $-2.2--0.6$ & 1050 & 5.0 & -3.77 & 0.22 & 0.38 & Meta-stable & -3.50 & 54.97 \\
\hline 14 & & TW1 & $-1.3-0.5$ & 300 & 3.5 & -3.50 & 0.26 & 0.11 & Meta-stable & -2.74 & 22.48 \\
\hline 15 & & TW2 & $-1.1-0.2$ & 1000 & 6.0 & -2.74 & 0.24 & 0.17 & Meta-stable & -2.60 & 55.71 \\
\hline 16 & & OW2 & $-1.9--0.2$ & $74\left(\mathrm{~N}_{\mathrm{f}}=74\right)$ & 4.0 & -2.60 & 0.33 & 0.40 & Unstable & -2.30 & 30.7 \\
\hline
\end{tabular}




\begin{tabular}{|c|c|c|c|c|c|c|c|c|c|c|c|}
\hline No. & $\begin{array}{c}\text { Test } \\
\text { Series }^{1,2,3}\end{array}$ & $\begin{array}{l}\text { Test } \\
\text { code }\end{array}$ & $\begin{array}{c}\text { Jack load } \\
(k N)\end{array}$ & $\begin{array}{c}\mathrm{N} \\
\text { cycles }\end{array}$ & $\begin{array}{c}\text { Rate } \\
\text { (N/min) }\end{array}$ & $\begin{array}{c}\text { Referential } \\
\mathbf{Q}_{\mathrm{T}}(\mathrm{kN})\end{array}$ & $\begin{array}{c}\mathbf{Q}_{\text {cyclicl }} \\
\mathbf{Q}_{\mathrm{T}}\end{array}$ & $\begin{array}{c}\mathbf{Q}_{\text {mean }} I \\
\mathbf{Q}_{\mathrm{T}}\end{array}$ & Description & $\begin{array}{c}\text { Post cycling } \\
\text { tensile capacity } \\
(k N)\end{array}$ & $\begin{array}{c}k_{\mathrm{l}, \mathrm{N}=1} \\
(\mathrm{kN} / \mathrm{mm})\end{array}$ \\
\hline \multicolumn{12}{|c|}{ Dry GA39 sand with BC5 boundary condition and density indices $I_{D} \approx 40 \%$} \\
\hline 17 & \multirow{6}{*}{ ICP10 } & OW1 & $-1.7-0$ & 1000 & 4.92 & -7.35 & 0.11 & 0.12 & Stable & -7.68 & 61.56 \\
\hline 18 & & OW2 & $-3.0-0$ & 1000 & 4.29 & -7.68 & 0.19 & 0.20 & Stable & -8.20 & 50.56 \\
\hline 19 & & OW3 & $-4.25--2.0$ & 1000 & 6.94 & -8.20 & 0.13 & 0.39 & Stable & -6.16 & 68.50 \\
\hline 20 & & OW4 & $-3.4-0$ & $500\left(\mathrm{~N}_{\mathrm{f}}=587^{3}\right)$ & 3.96 & -6.16 & 0.27 & 0.28 & Metastable & -4.25 & 40.37 \\
\hline 21 & & TW1 & $-2.4--1.3$ & $2\left(N_{f}=1\right)$ & 2 & -4.25 & 0.43 & 0.14 & Unstable & -2.95 & 2.50 \\
\hline 22 & & TW2 & $-0.87--0.9$ & 250 & 4.71 & & 0.21 & 0.00 & Metastable & & 6.58 \\
\hline
\end{tabular}

${ }^{1}$ Tests ICP 01 to ICP03 are summarised by Tsuha et al. 2012.

2 Tests conducted under displacement control with cyclic amplitude of +0.5 to $-0.5 \mathrm{~mm}$.

${ }^{3}$ Estimated number of cycles at failure

Table 2: Axial cyclic loading test series using Mini-ICP. 


\begin{tabular}{|c|c|c|c|c|c|c|c|c|c|c|c|}
\hline No. & $\begin{array}{c}\text { Test } \\
\text { series }\end{array}$ & $\begin{array}{l}\text { Test } \\
\text { code }\end{array}$ & $\begin{array}{c}\text { Jack load } \\
(k N)\end{array}$ & $\mathrm{N}$ cycles & $\begin{array}{c}\text { Rate } \\
\text { (N/min) }\end{array}$ & $\begin{array}{c}\text { Referential } \\
\qquad \mathbf{Q}_{\mathrm{T}}(\mathbf{k N})\end{array}$ & $\mathbf{Q}_{\text {cyclic }} / \mathbf{Q}_{\mathbf{T}}$ & $\mathbf{Q}_{\text {mean }} / \mathbf{Q}_{\mathrm{T}}$ & Description & $\begin{array}{l}\text { Post cycling } \\
\text { tensile } \\
\text { capacity (kN) }\end{array}$ & $\begin{array}{c}k_{\mathrm{l}, \mathrm{N}=1} \\
(\mathrm{kN} / \mathrm{mm})\end{array}$ \\
\hline \multicolumn{12}{|c|}{ Dry NE34 with BC1 boundary condition and density indices $I_{D} \approx 70 \%$} \\
\hline 5 & \multirow{7}{*}{ DTV } & OW1 & $-1.57-0$ & 1800 & 4.9 & -7.38 & 0.10 & 0.11 & Stable & -7.75 & 57.63 \\
\hline 6 & & OW2 & $-2.84-0.53$ & 1000 & 3.0 & -7.75 & 0.15 & 0.22 & Stable & -7.60 & 88.46 \\
\hline 7 & & OW3 & $-3.75--2.35$ & 1000 & 4.6 & -7.60 & 0.09 & 0.40 & Stable & -7.32 & 291.78 \\
\hline 8 & & OW4 & $-4.94--0.75$ & $71\left(\mathrm{~N}_{\mathrm{f}}=71\right)$ & 2,2 & -7.32 & 0.29 & 0.39 & Unstable & -6.86 & 90.91 \\
\hline 9 & & TW1 & $-2.22-0.74$ & 670 & 2,6 & -6.86 & 0.22 & 0.11 & Meta-stable & -6.66 & 33.13 \\
\hline 10 & & TW2 & $-2.85-2.13$ & $23\left(N_{f}=23\right)$ & 0,82 & -6.66 & 0.38 & 0.05 & Unstable & -4.10 & 4.43 \\
\hline 11 & & OW5 & $-1.15-0$ & 1500 & 4.4 & -4.10 & 0.13 & 0.15 & Meta-Stable & -5.55 & 50.71 \\
\hline \multicolumn{12}{|c|}{ Dry NE34 with BC5 boundary condition and density indices $I_{D} \approx 70 \%$} \\
\hline 1 & \multirow{2}{*}{ DTIII } & OW1 & $-3.1-0$ & 1000 & 3.7 & -7.40 & 0.21 & 0.21 & Meta-Stable & -8.70 & 70.24 \\
\hline 2 & & OW2 & $-2.3-0$ & 1000 & 5.0 & -8.70 & 0.14 & 0.13 & Meta-Stable & -8.30 & 94.71 \\
\hline 3 & \multirow{2}{*}{ DTIV } & OW1 & $-1.6-0$ & 1000 & 4.8 & -6.98 & 0.12 & 0.12 & Stable & -7.81 & 63.07 \\
\hline 4 & & OW2 & $-3.0-0$ & $410\left(\mathrm{~N}_{\mathrm{f}}=410\right)$ & 3.2 & -7.81 & 0.20 & 0.20 & Meta-stable & -7.69 & 66.13 \\
\hline 12 & \multirow{6}{*}{ DTVI $^{1}$} & OW1 & $-2.35--1.19$ & 2000 & 3.9 & -6.79 & 0.09 & 0.26 & Stable & -7.24 & 105.27 \\
\hline 13 & & OW2 & $-4.65--2.55$ & 1500 & 3.3 & -7.24 & 0.15 & 0.50 & Meta-Stable & $-7-27$ & 104.80 \\
\hline 14 & & OW3 & $-3.61--0.75$ & $616\left(N_{f}=616\right)$ & 3.0 & $-7-27$ & 0.20 & 0.30 & Meta-stable & -7.13 & 92.89 \\
\hline 15 & & OW4 & $-5.55--0.75$ & $22\left(\mathrm{~N}_{\mathrm{f}}=22\right)$ & 1.7 & -7.13 & 0.34 & 0.44 & Unstable & -7.00 & 25.16 \\
\hline 16 & & TW1 & $-3.09-0.94$ & $44\left(\mathrm{~N}_{\mathrm{f}}=44\right)$ & 1.9 & -7.00 & 0.26 & 0.18 & Unstable & -6.39 & 45.56 \\
\hline 17 & & TW2 & $-3.73-2.41$ & $11\left(\mathrm{~N}_{\mathrm{f}}=11\right)$ & 0.6 & -6.39 & 0.39 & 0.14 & Unstable & -4.44 & 5.05 \\
\hline 18 & $\mathrm{DTVII}^{2}$ & OW1 & $-5.30--3.82$ & 2700 & 3.3 & -7.54 & 0.10 & 0.60 & Stable & -8.24 & 71.02 \\
\hline
\end{tabular}




\begin{tabular}{|c|c|c|c|c|c|c|c|c|c|c|c|}
\hline No. & $\begin{array}{c}\text { Test } \\
\text { series }\end{array}$ & $\begin{array}{l}\text { Test } \\
\text { code }\end{array}$ & $\begin{array}{c}\text { Jack load } \\
\text { (kN) }\end{array}$ & N cycles & $\begin{array}{c}\text { Rate } \\
\text { (N/min) }\end{array}$ & $\begin{array}{l}\text { Referential } \\
\qquad \mathbf{Q}_{\mathrm{T}}(\mathbf{k N})\end{array}$ & $\mathbf{Q}_{\text {cyclic }} / \mathbf{Q}_{\mathbf{T}}$ & $\mathbf{Q}_{\text {mean }} / \mathbf{Q}_{\mathbf{T}}$ & Description & $\begin{array}{l}\text { Post cycling } \\
\text { tensile } \\
\text { capacity (kN) }\end{array}$ & $\begin{array}{c}k_{\mathrm{l}, \mathrm{N}=1} \\
(\mathrm{kN} / \mathrm{mm})\end{array}$ \\
\hline 19 & & OW2 & $-7.27--2.52$ & $18\left(\mathrm{~N}_{\mathrm{f}}=18\right)$ & 1.8 & -8.24 & 0.29 & 0.59 & Unstable & -8.34 & 15.44 \\
\hline 20 & & OW3 & $-4.97--0.07$ & $59\left(N_{f}=59\right)$ & 2.2 & -8.34 & 0.29 & 0.30 & Unstable & -7.96 & 36.57 \\
\hline 21 & & TW1 & $-5.83-0.51$ & $14\left(\mathrm{~N}_{\mathrm{f}}=14\right)$ & 1.5 & -7.96 & 0.38 & 0.35 & Unstable & -8.01 & 25.30 \\
\hline
\end{tabular}

${ }^{1}$ Lateral membranes' pressure were modified continuously during pile installation to minimize lateral volume variations.

${ }^{2} \mathrm{~A}$ pre imposed lateral confinement profile was imposed bases on jacked tests ICP07 and ICP08 lateral membranes responses.

Table 3: Axial cyclic loading test series using driven piles 


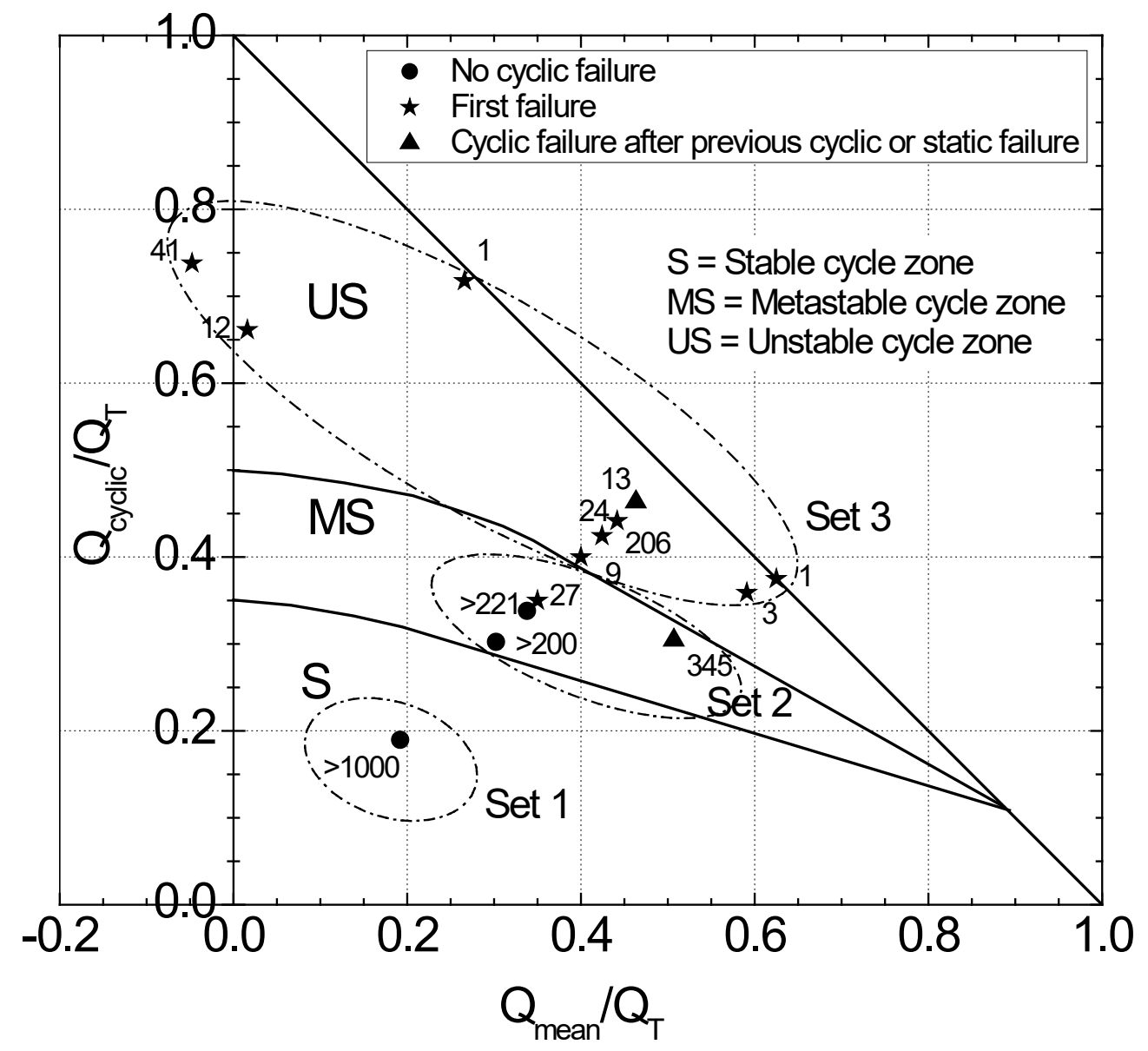

Fig. 1: Axial cyclic interaction diagram for the full-scale pile tests in Dunkirk silica marine sands (after Jardine \& Standing 2012) 


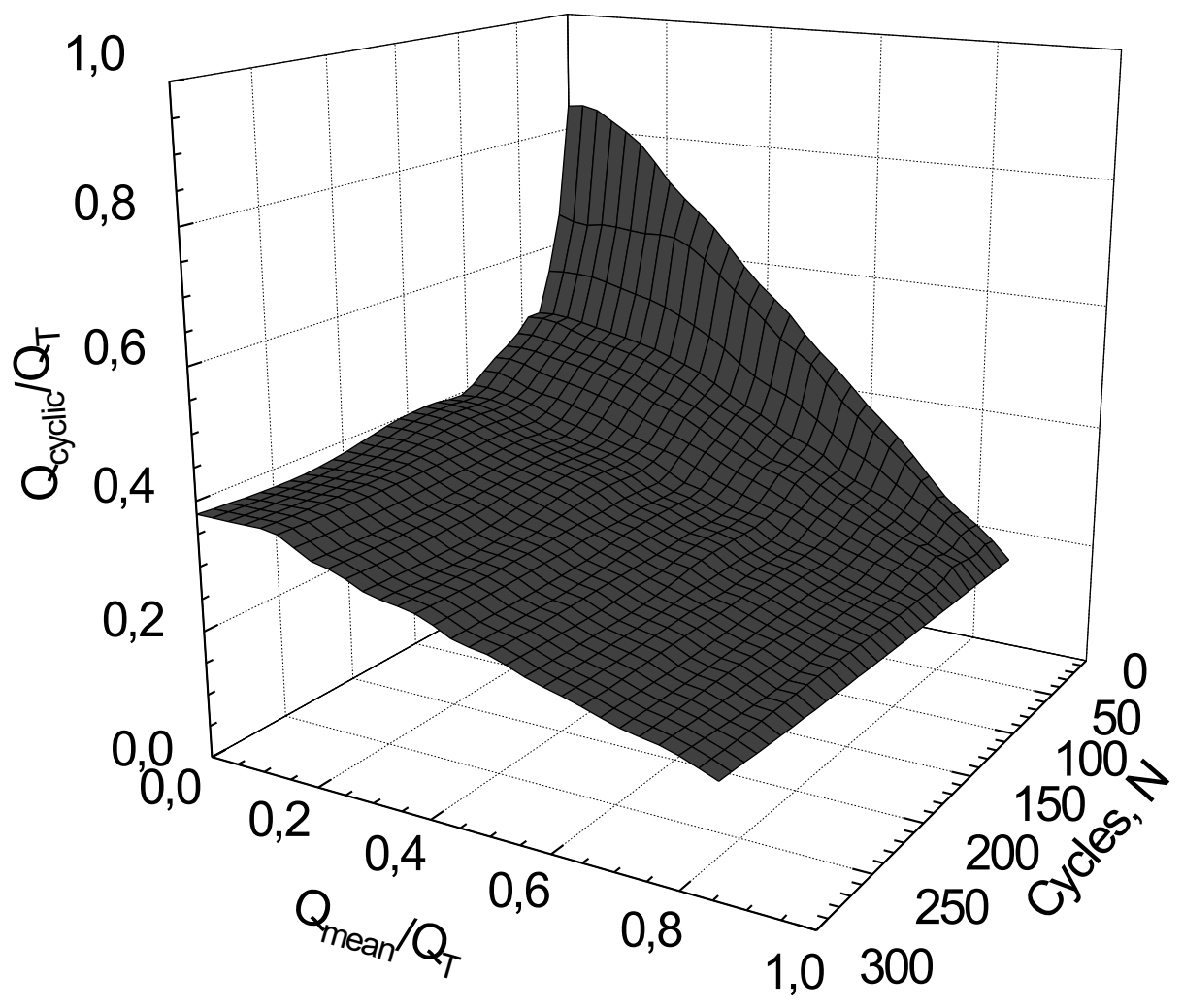

Fig. 2: $3 \mathrm{D}$ plot for permanent accumulated cyclic displacements equivalent to $2 \%$ diameter (D) for Dunkirk field cyclic loading tests, after Rimoy et al. (2013). 


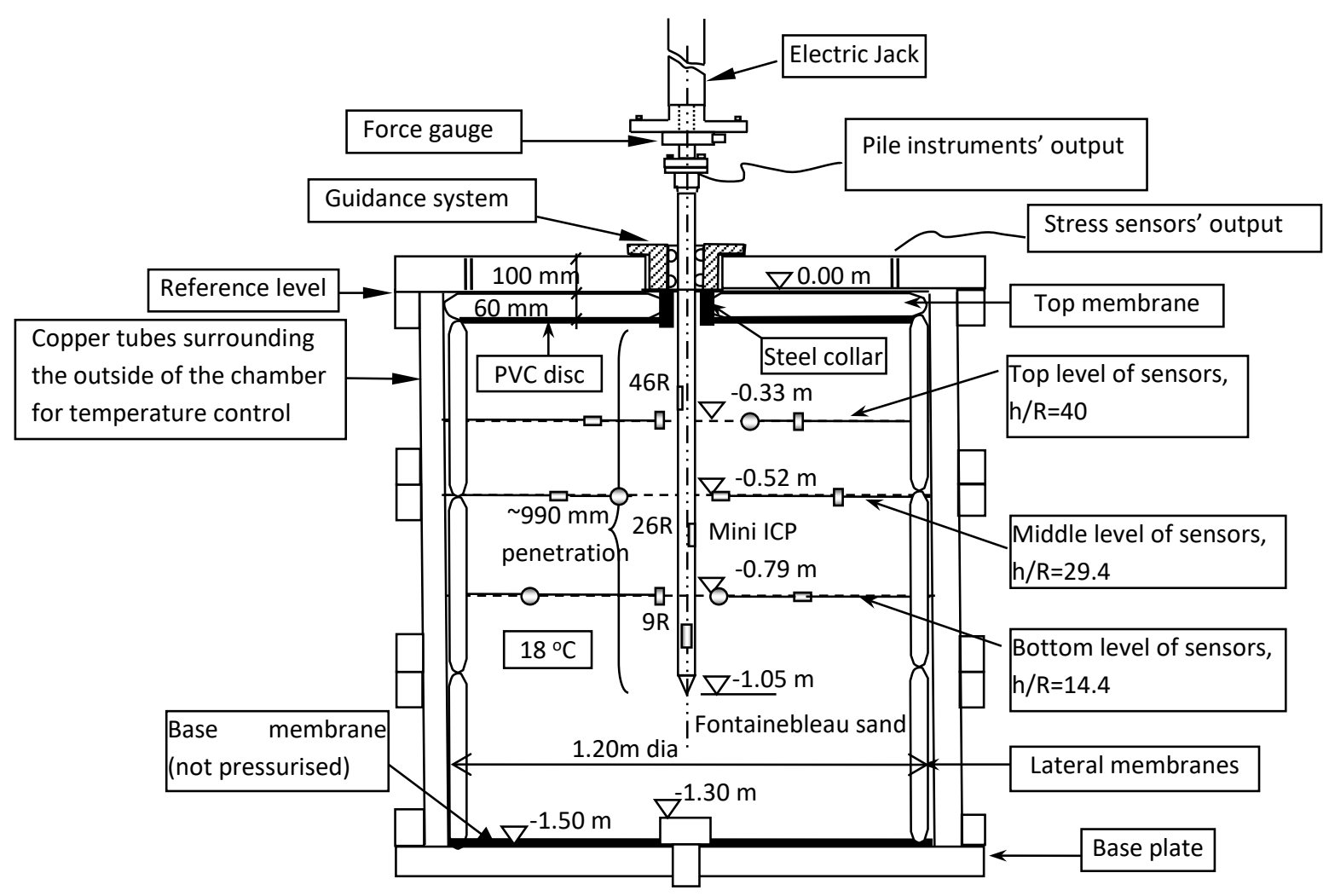

Fig. 3: Calibration Chamber and Mini-ICP arrangements of tests ICP07 and 08; vertical section after Rimoy (2013). Pile sensors h=9R above tip are 'Leading', at 26R are 'Following', and at $46 \mathrm{R}$ are 'Trailing'. 


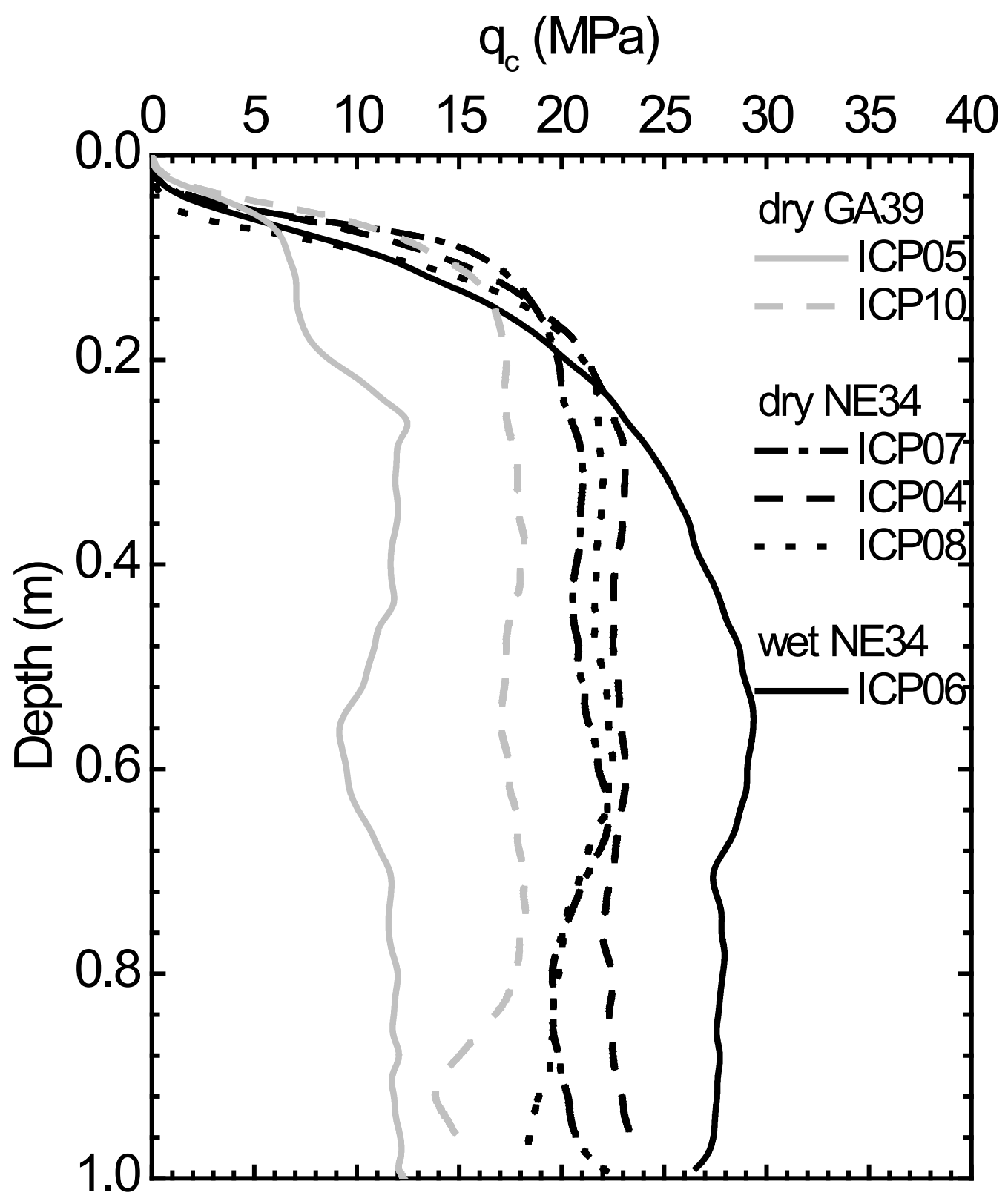

Figure 4: Pile end-bearing resistances for Mini-ICP pile jacked tests in this study 


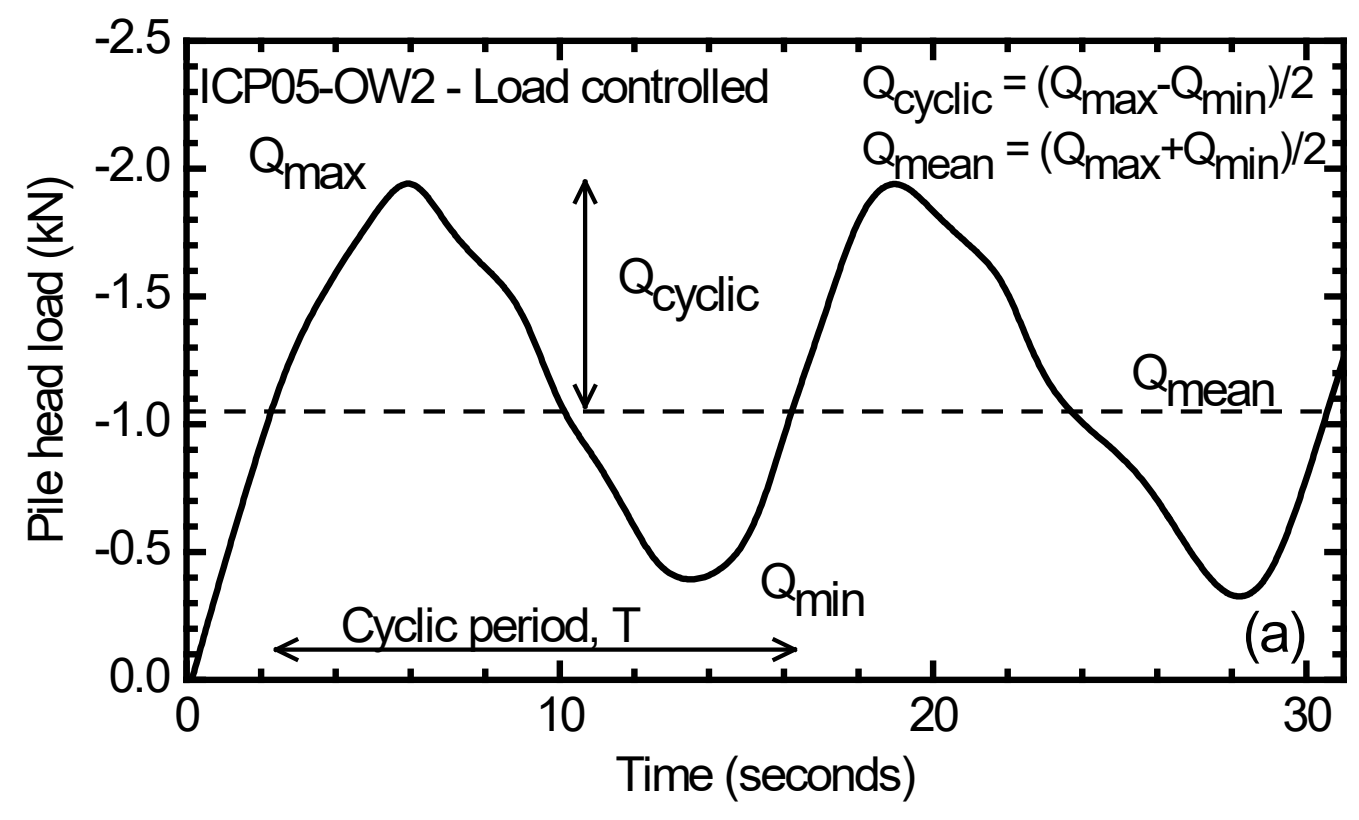

Fig. 5: Example of axial cyclic loading load patterns illustrated from load controlled test ICP05OW2 


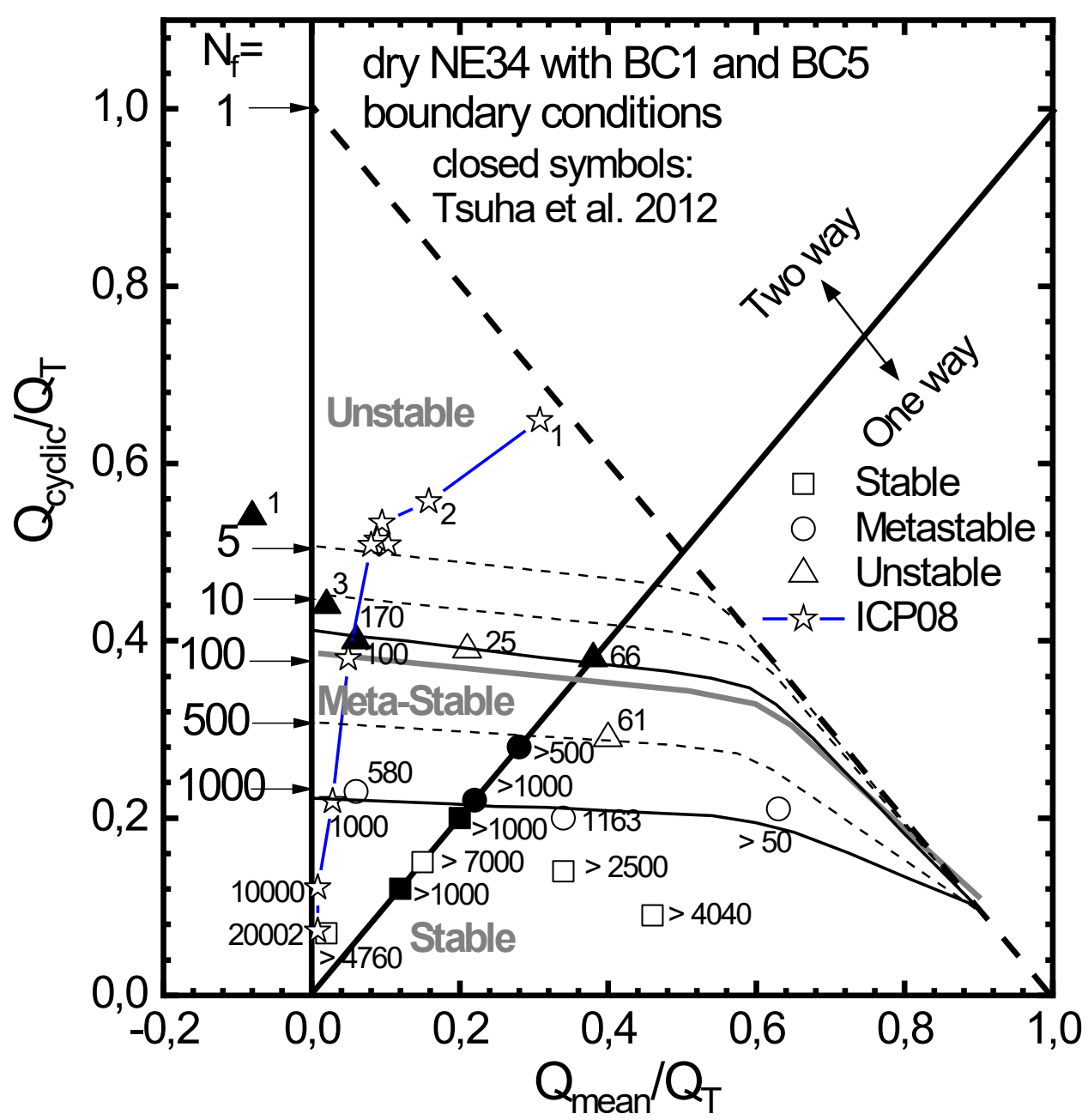

Fig. 6a: Axial cyclic loading interaction diagram with the Mini-ICP in dry NE34 sand 


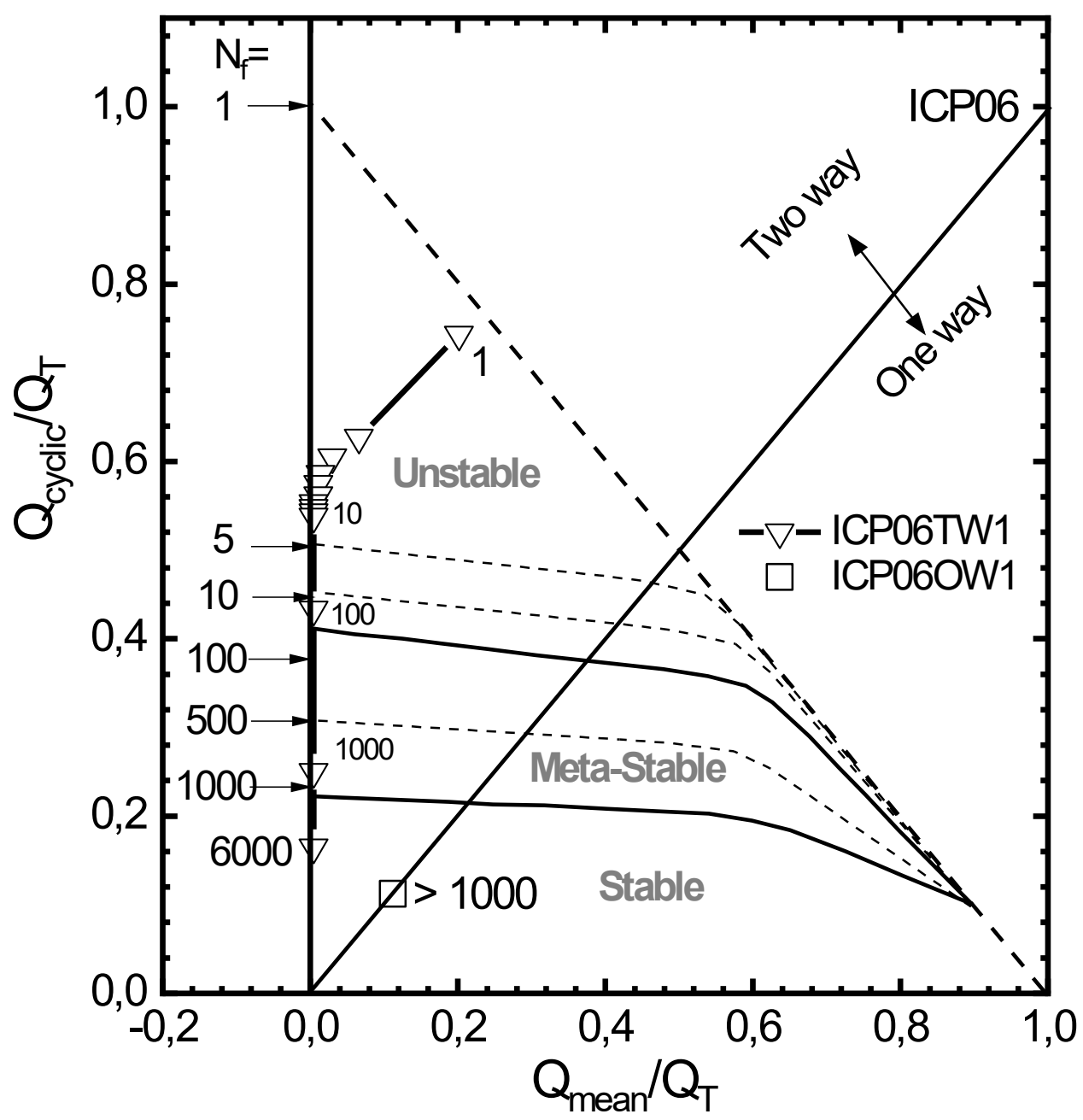

Fig. 6b: Axial cyclic loading interaction diagram for ICP06 with Mini-ICP in wet NE34 sand 


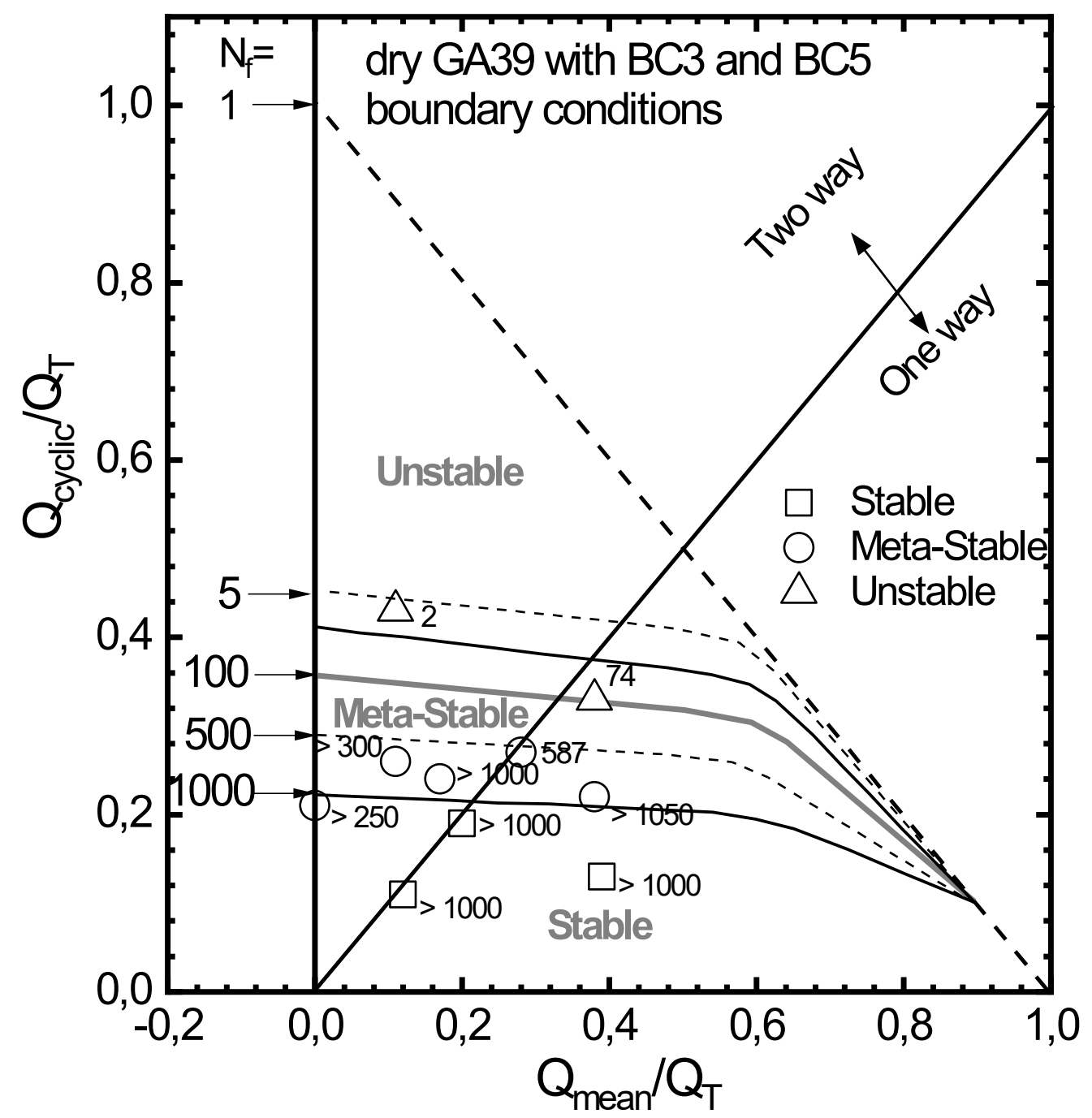

Fig. 6c: Axial cyclic loading interaction diagram with the Mini-ICP in dry GA39 sand 


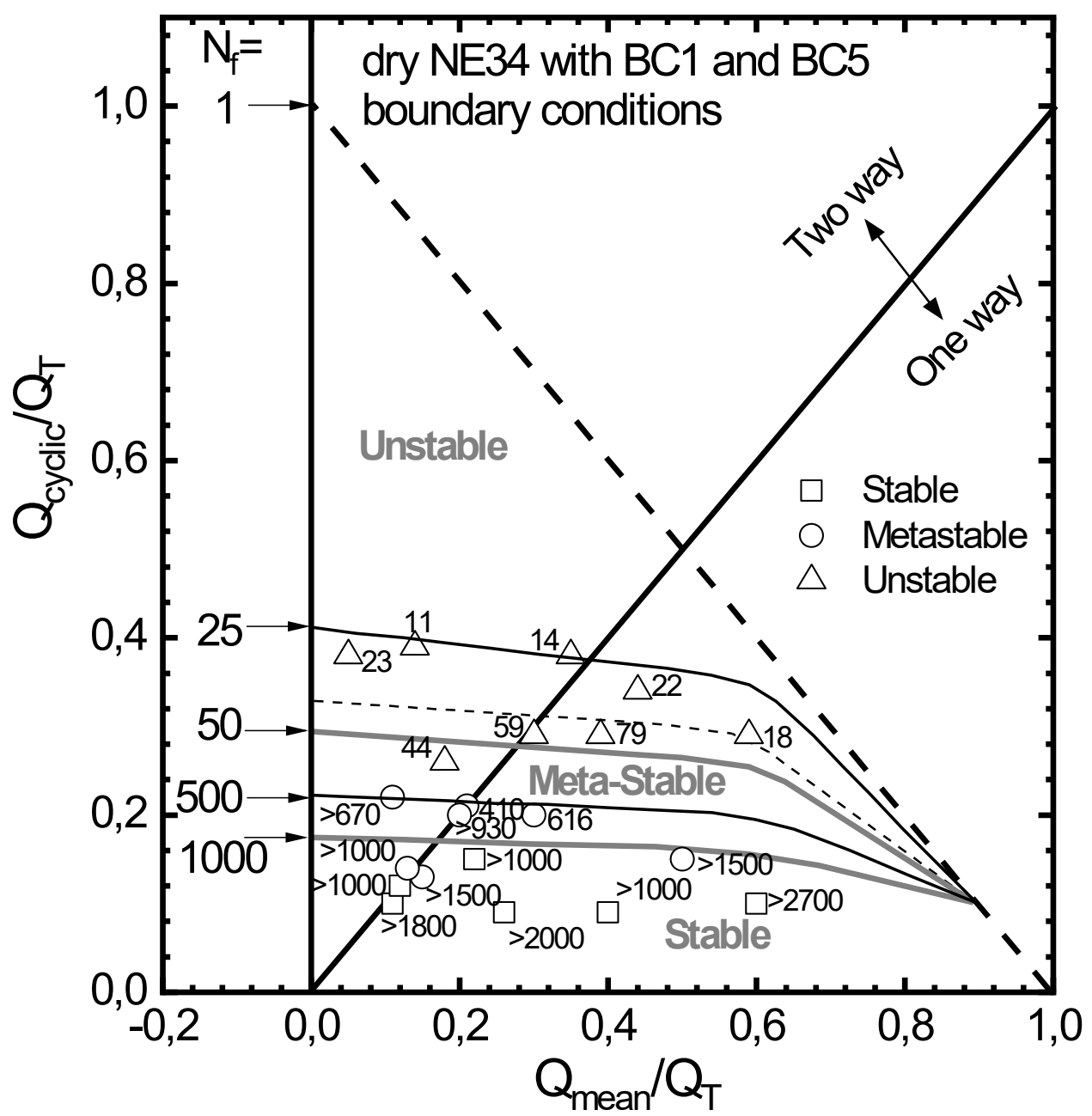

Fig. 6d: Axial cyclic loading interaction diagram for Driven tests in dry NE34 sand 


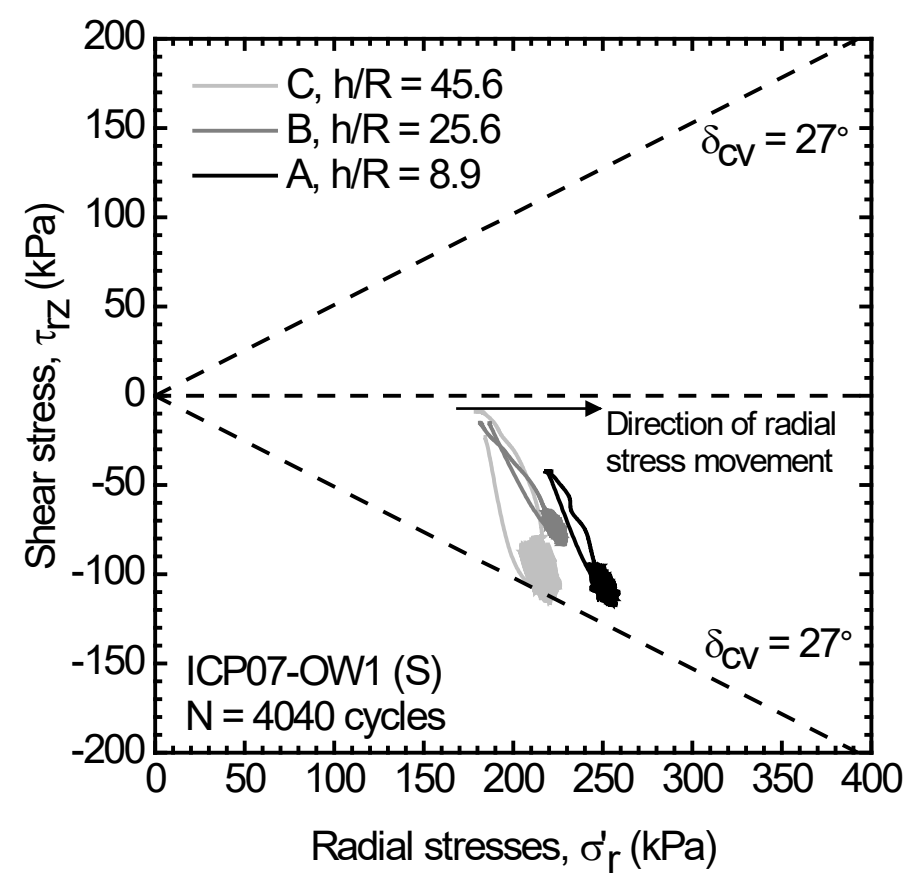

Fig. 7a Interface effective stress paths from stable one-way cyclic loading test ICP07OW1 in dry NE34 sand under BC5 boundary conditions

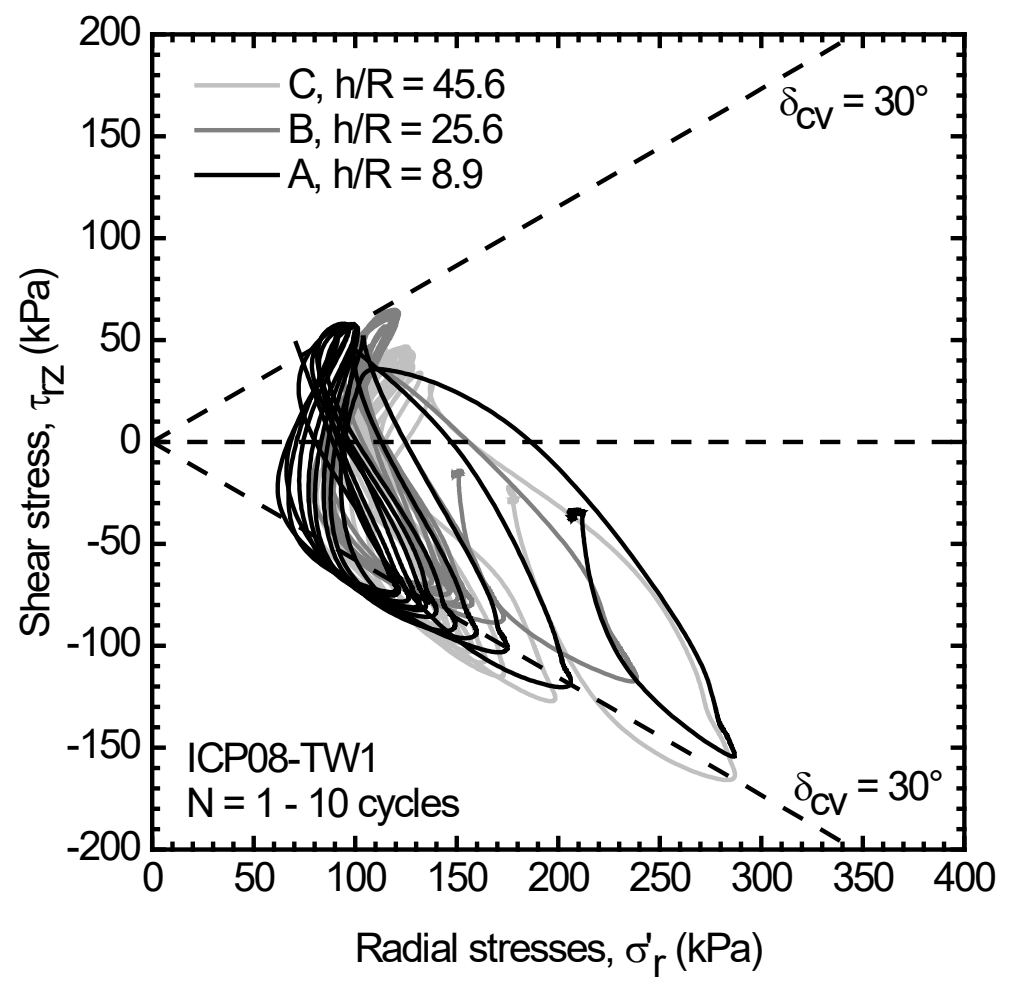

Fig. 7b: Interface effective stress paths from unstable two-way cyclic loading test ICP08-TW1 in dry NE34 sand under BC5 boundary conditions first 10 cycles. 


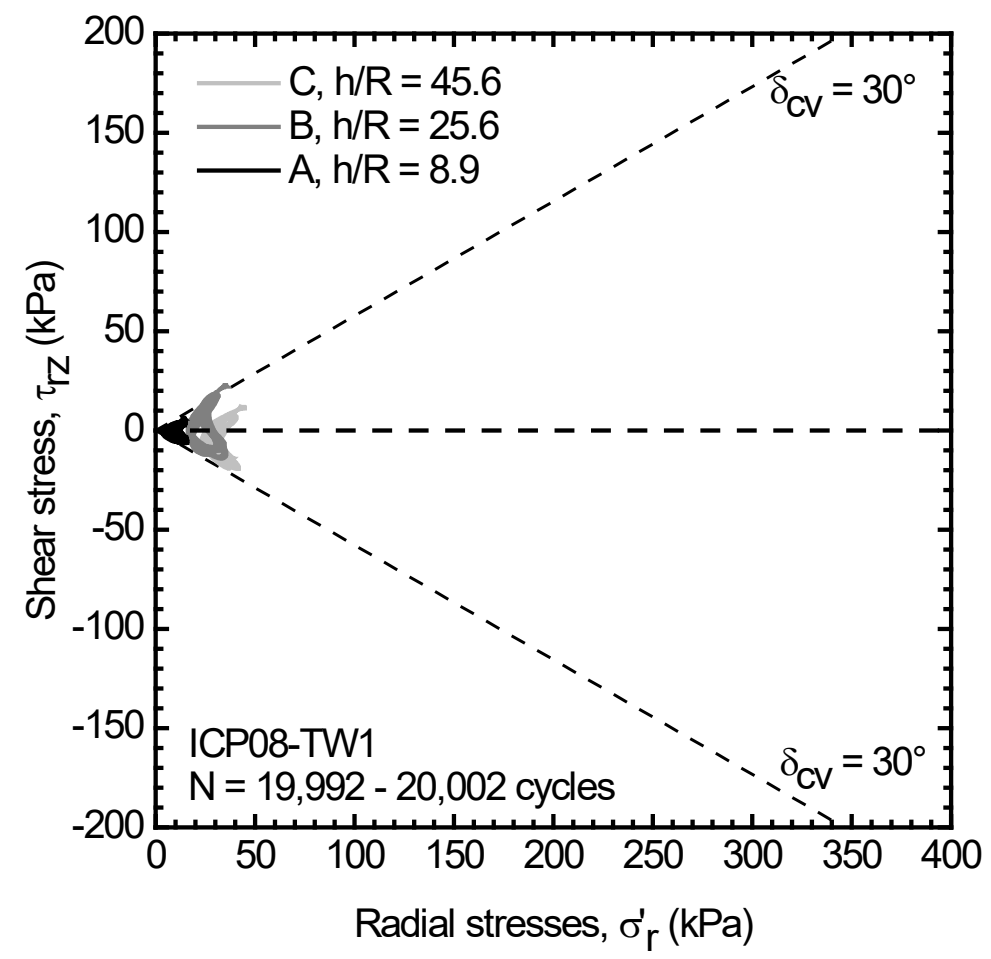

Fig. 7c: Interface effective stress paths from unstable two-way cyclic loading test ICP08-TW1 in dry NE34 sand under BC5 boundary conditions final 20 cycles 


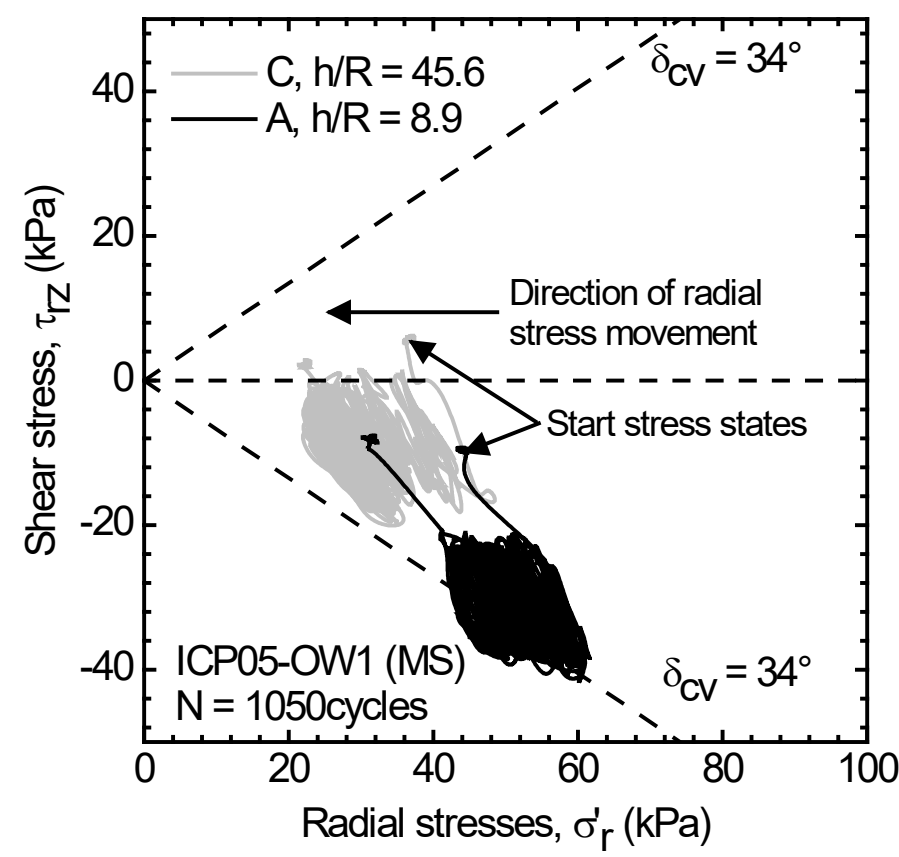

Fig. 8a: Interface effective stress paths from ICP05-OW1 one-way cyclic test on loose GA39 sand, BC3 boundary conditions, failed after 1050 cycles.

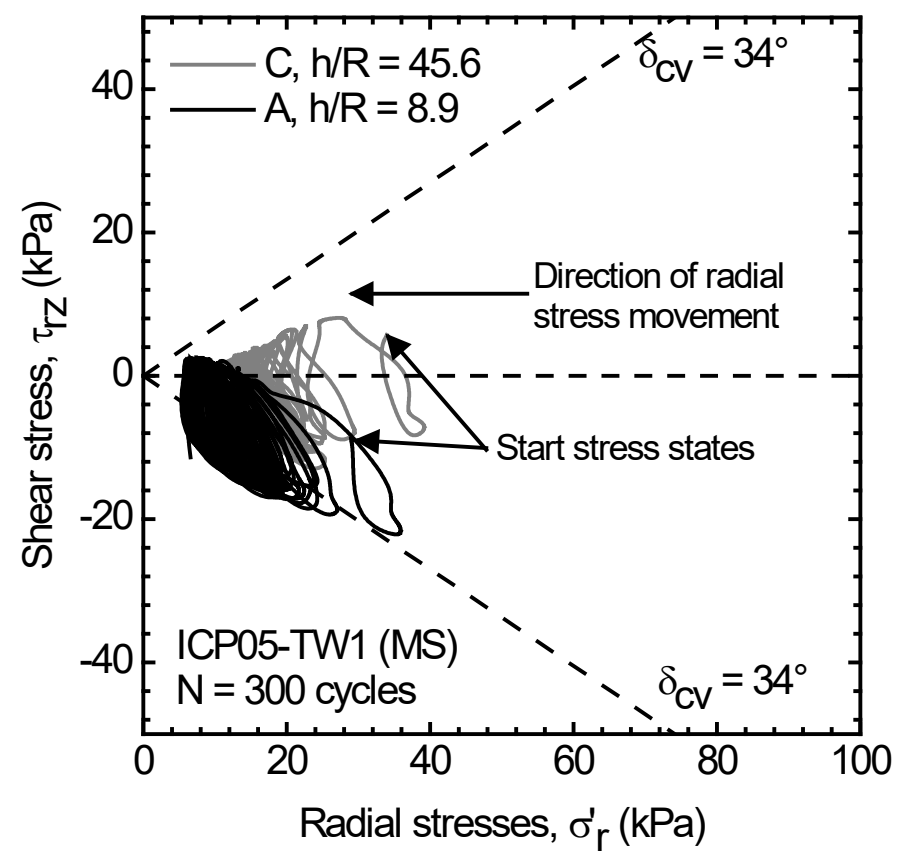

Fig. 8b: Interface effective stress paths from ICP05-TW1 two-way cyclic test on loose GA39 sand, BC3 boundary conditions, failed after 300 cycles. 


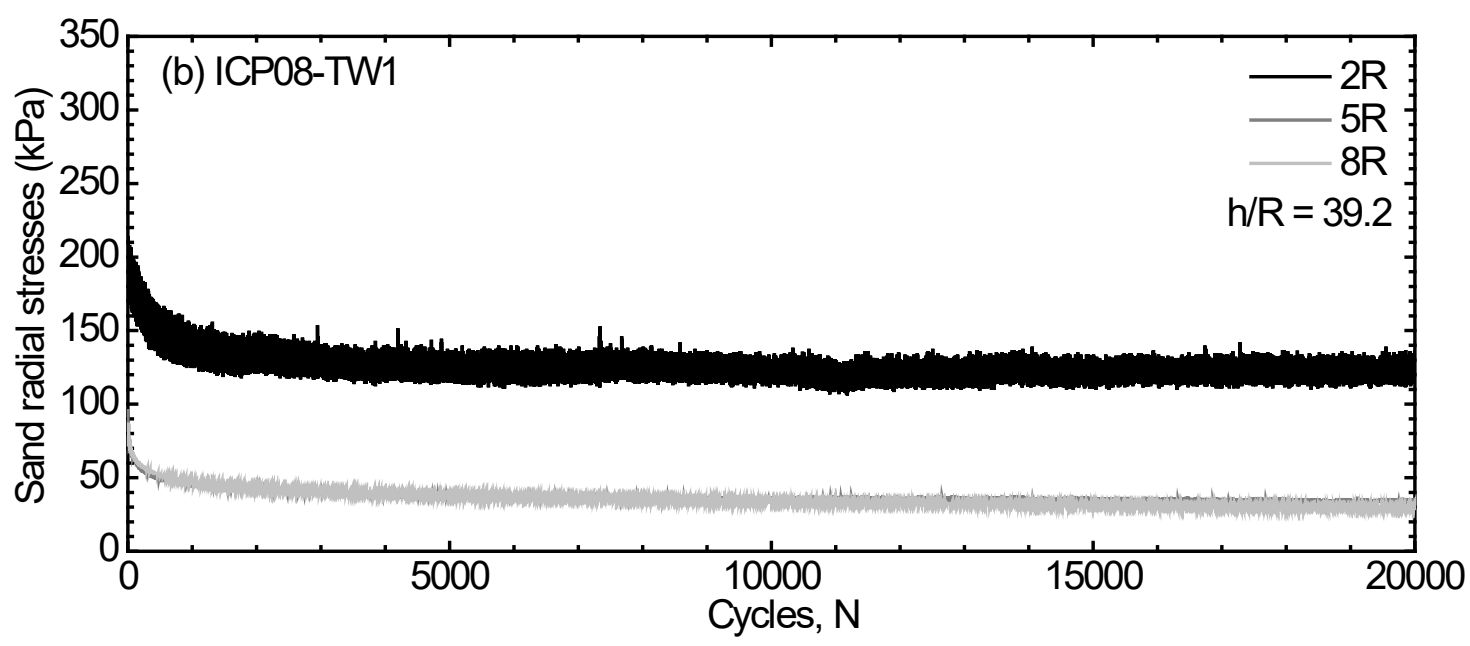

Fig. 9a: Sand mass radial stresses against the number of cycles applied in unstable two-way cyclic loading test ICP08-TW1 in dry NE34 sand under $+/-0.5 \mathrm{~mm}$ displacement control under with BC5 boundary conditions

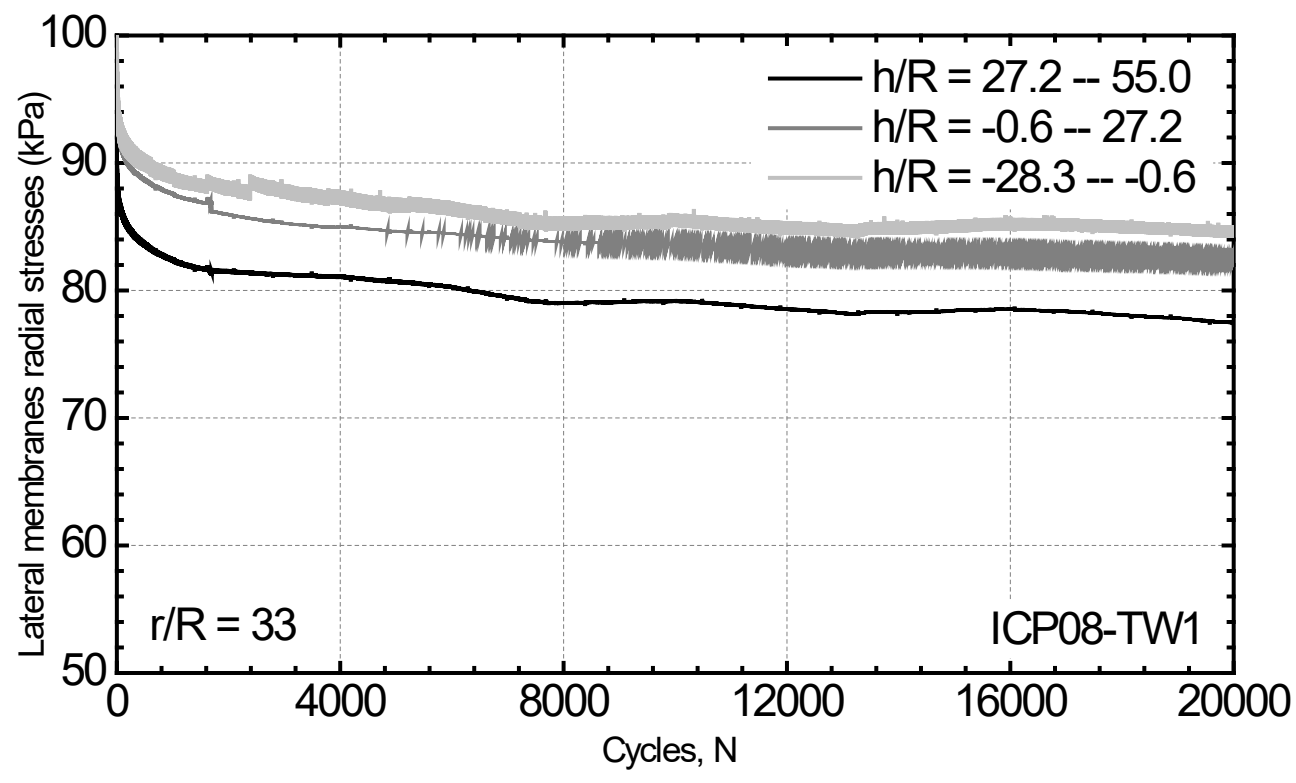

Fig. 9b: Radial stresses at the calibration chamber boundary against the number of cycles applied in unstable two-way cyclic loading test ICP08-TW1 in dry NE34 sand under $+/-0.5 \mathrm{~mm}$ displacement control under with BC5 boundary conditions 


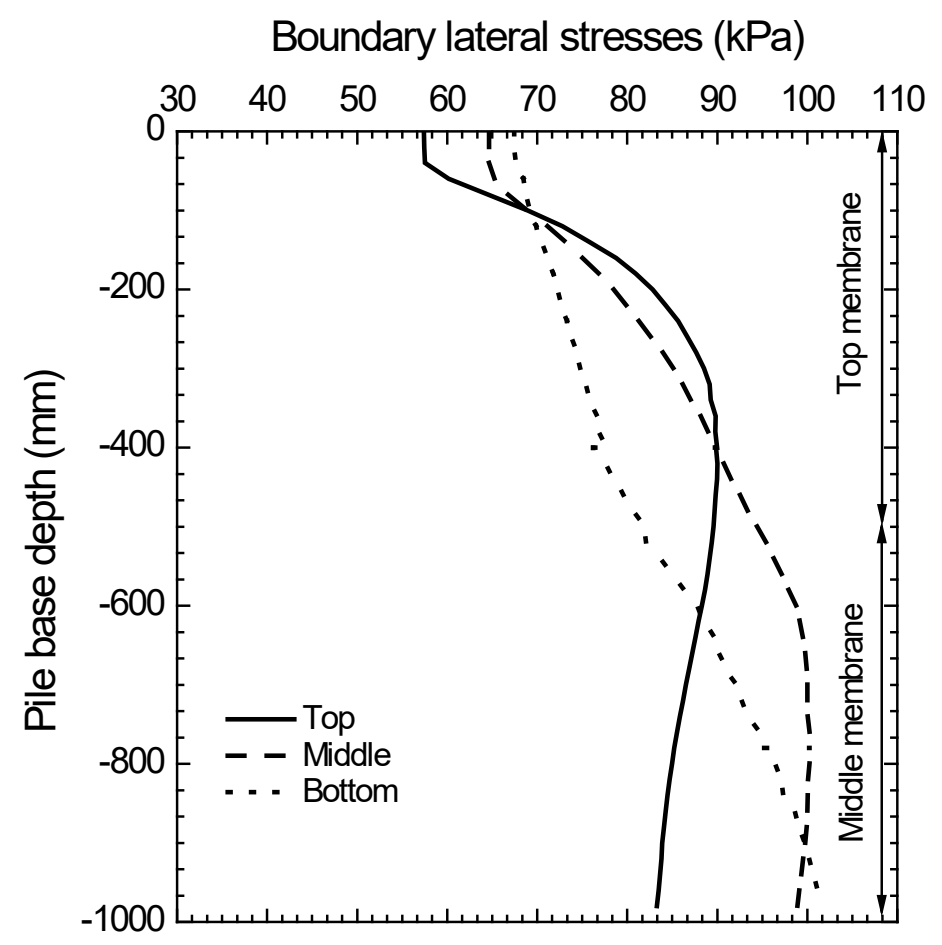

Fig. 10a: Lateral boundary stresses during installations in Mini-ICP test ICP08 with boundary condition BC5. 


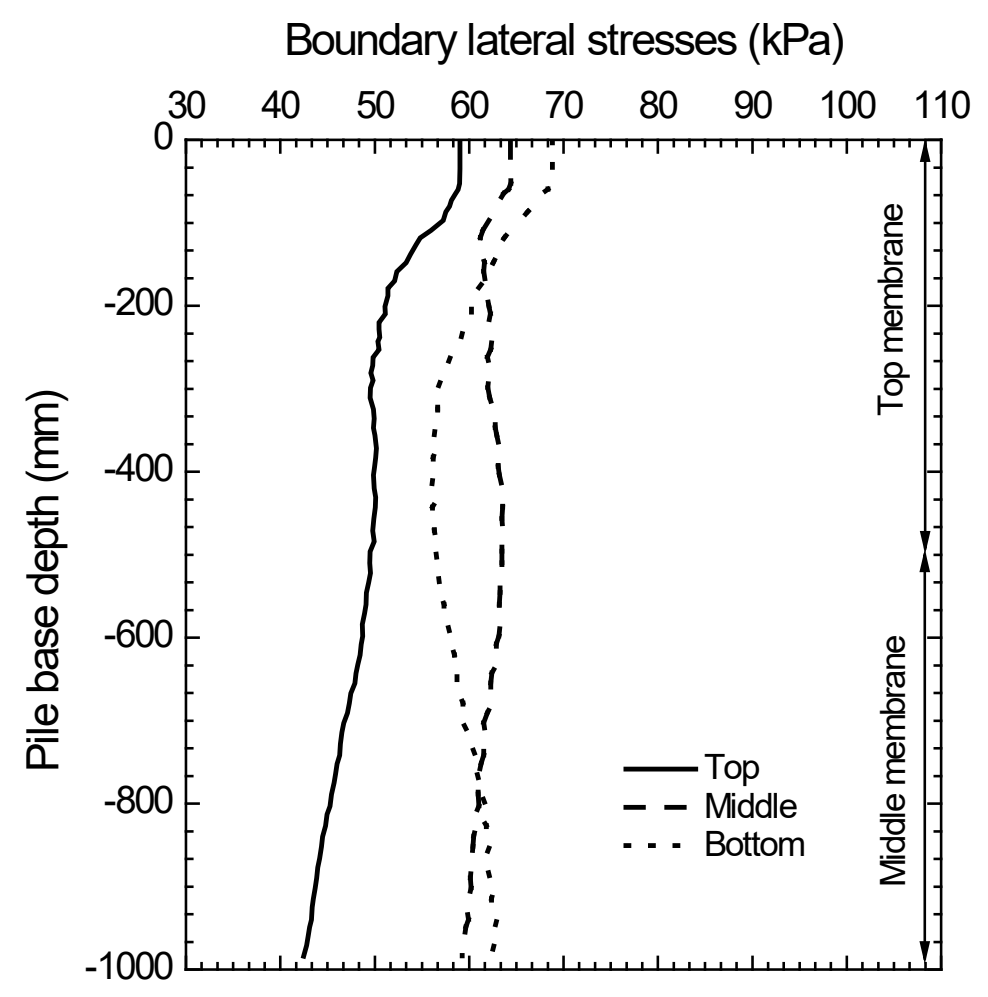

Fig. 10b: Lateral boundary stresses during installations in driven test DTIII with boundary condition BC5. 


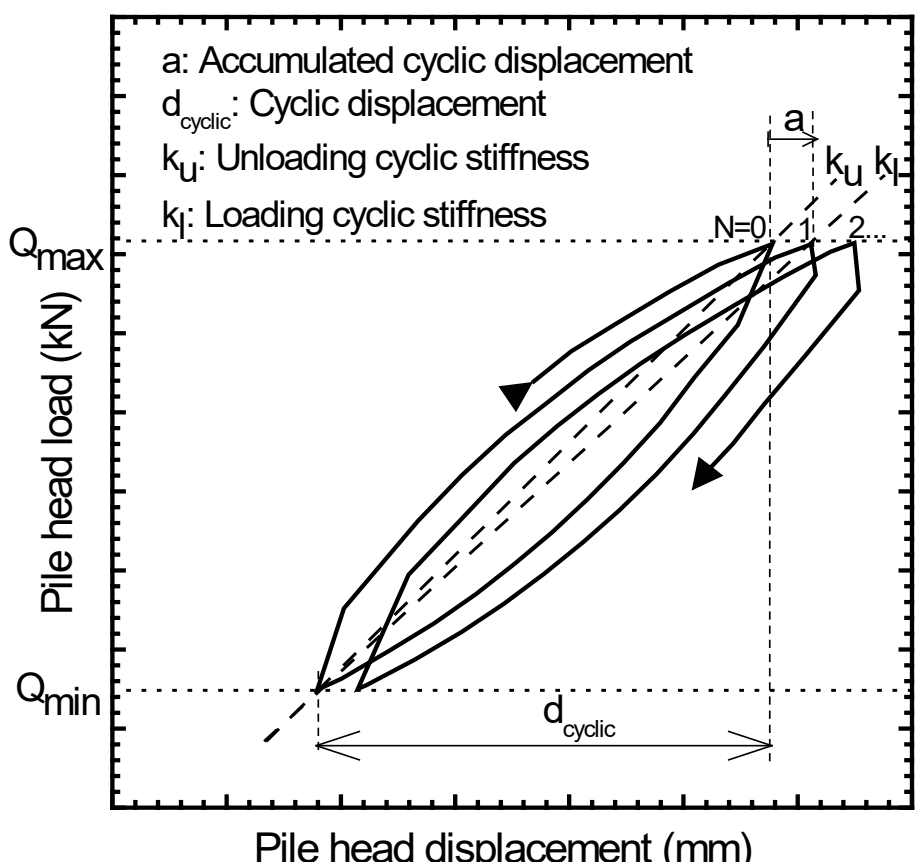

Fig. 11: Displacement and stiffness parameters employed in the analyses 


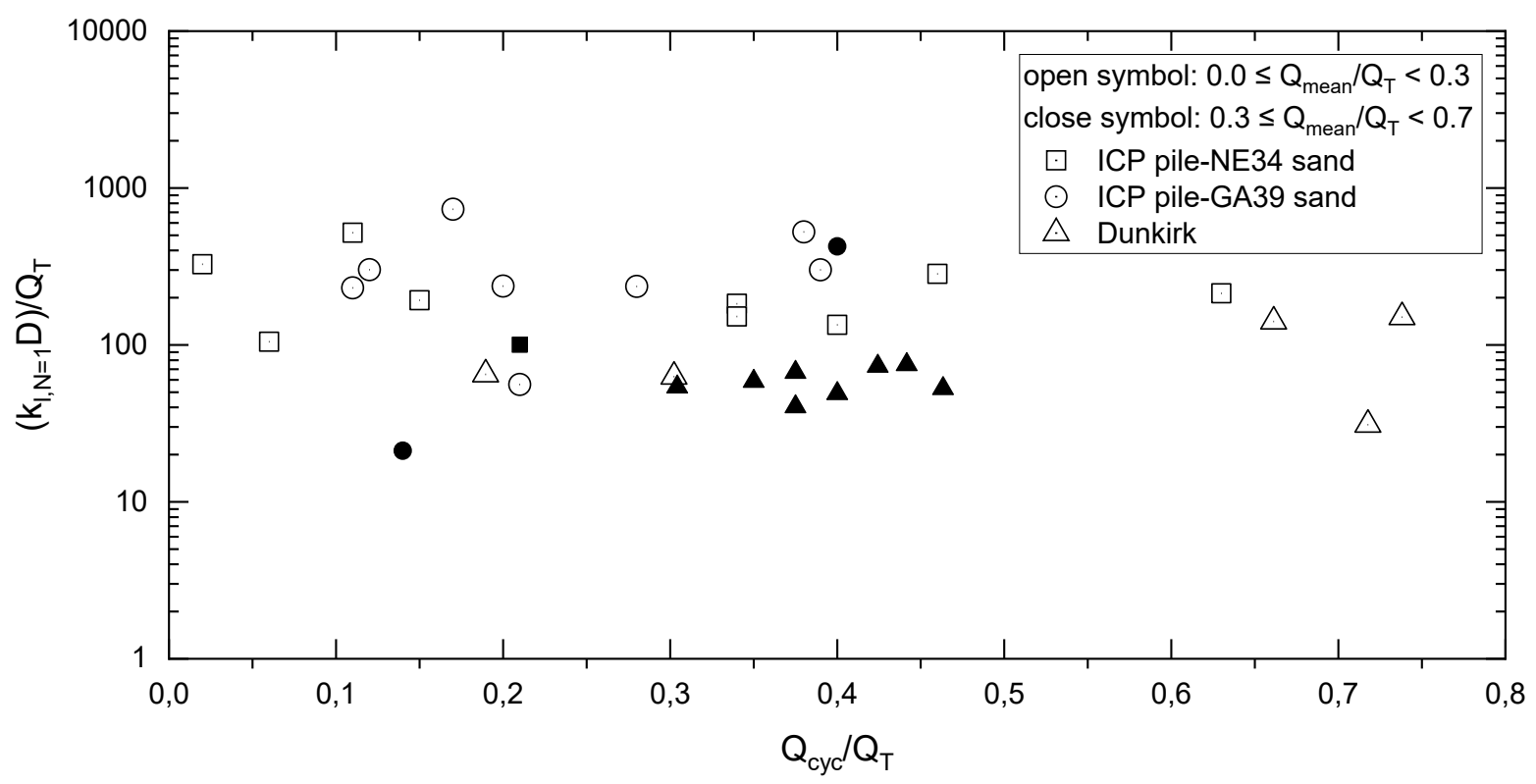

Fig. 12a: Non-dimensional stiffness $k_{l, N=1} D_{/} Q_{T}$ against $Q_{c y c} / Q_{T}$ for jacked pile tests

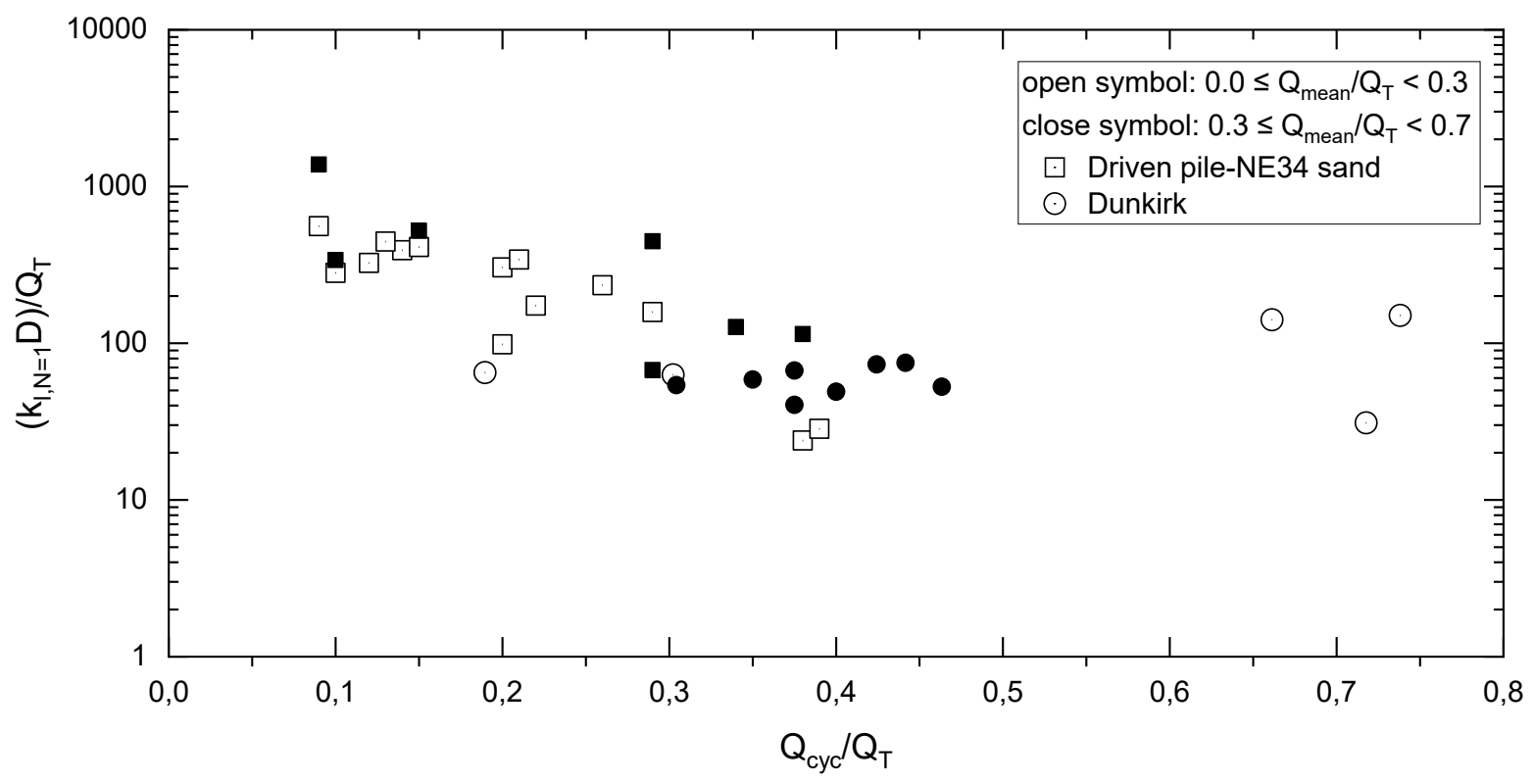

Fig. 12b: Non-dimensional stiffness kl,N=1 $D / Q_{T}$ against $Q_{c y c} / Q_{T}$ for driven pile tests 


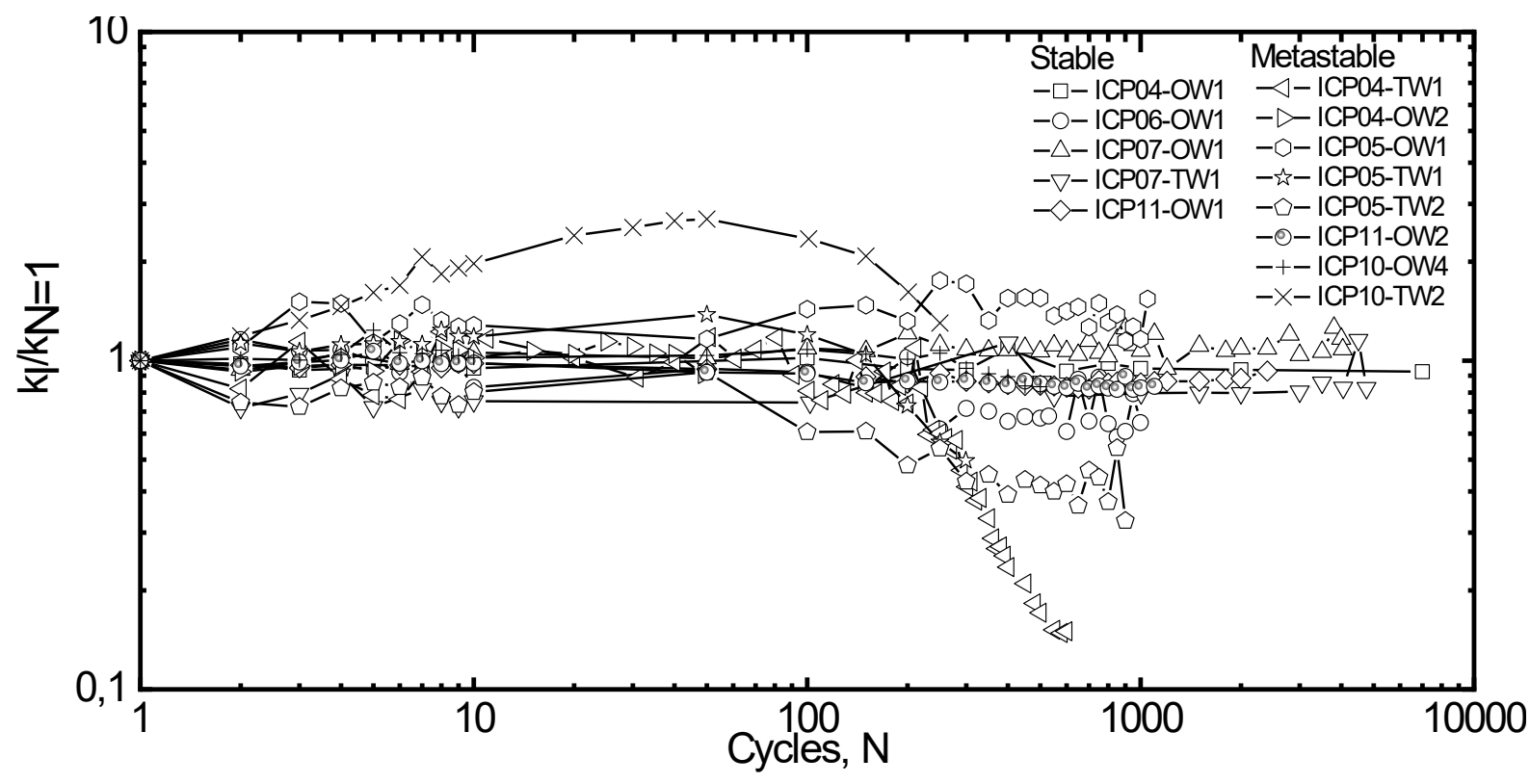

Fig. 13: Normalised axial cyclic pile stiffness versus number of cycles applied in stable and metastable cyclic loading tests for the ICP pile 


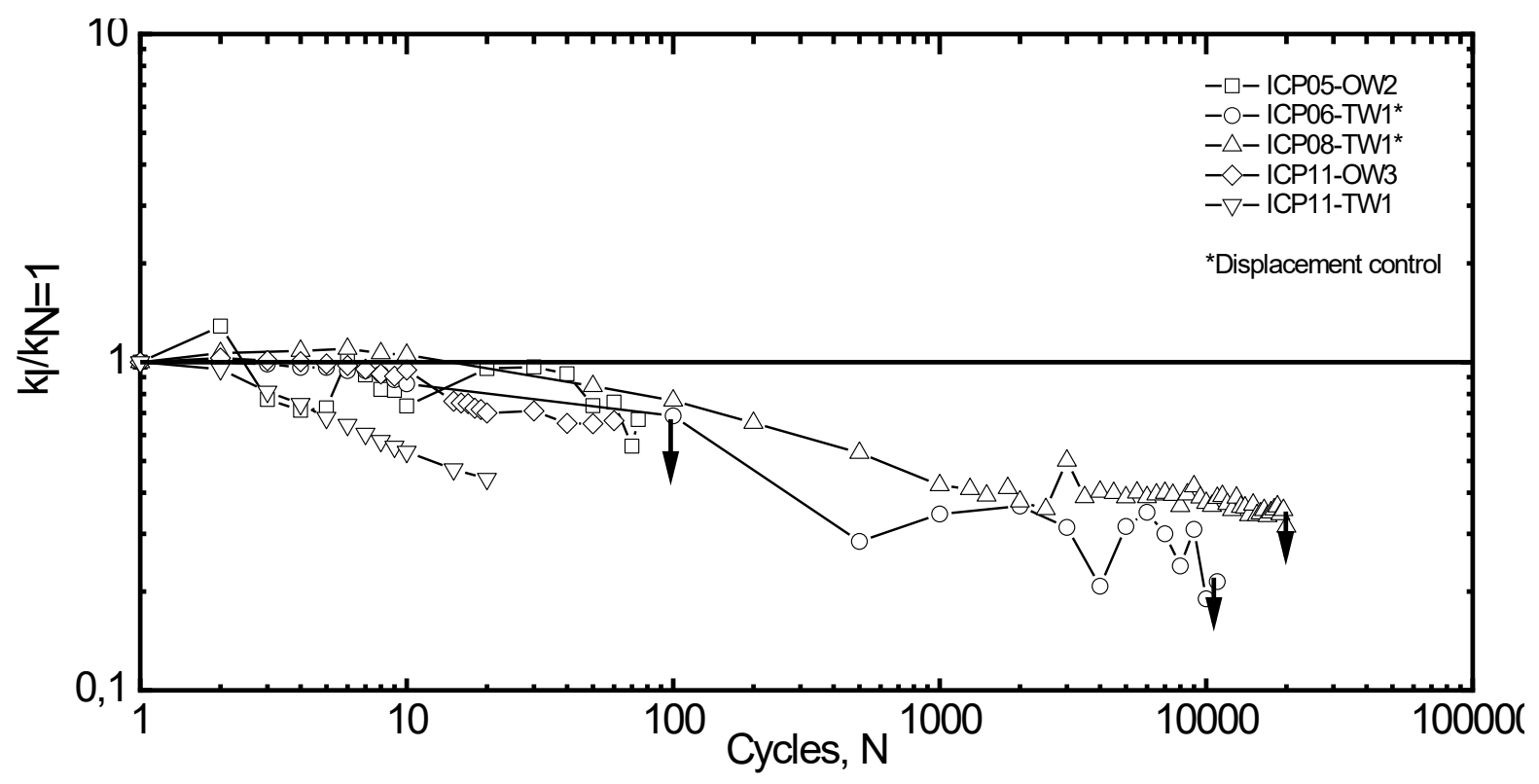

Fig. 14: Normalised axial cyclic pile stiffness versus number of cycles applied in unstable cyclic loading tests for the ICP pile 


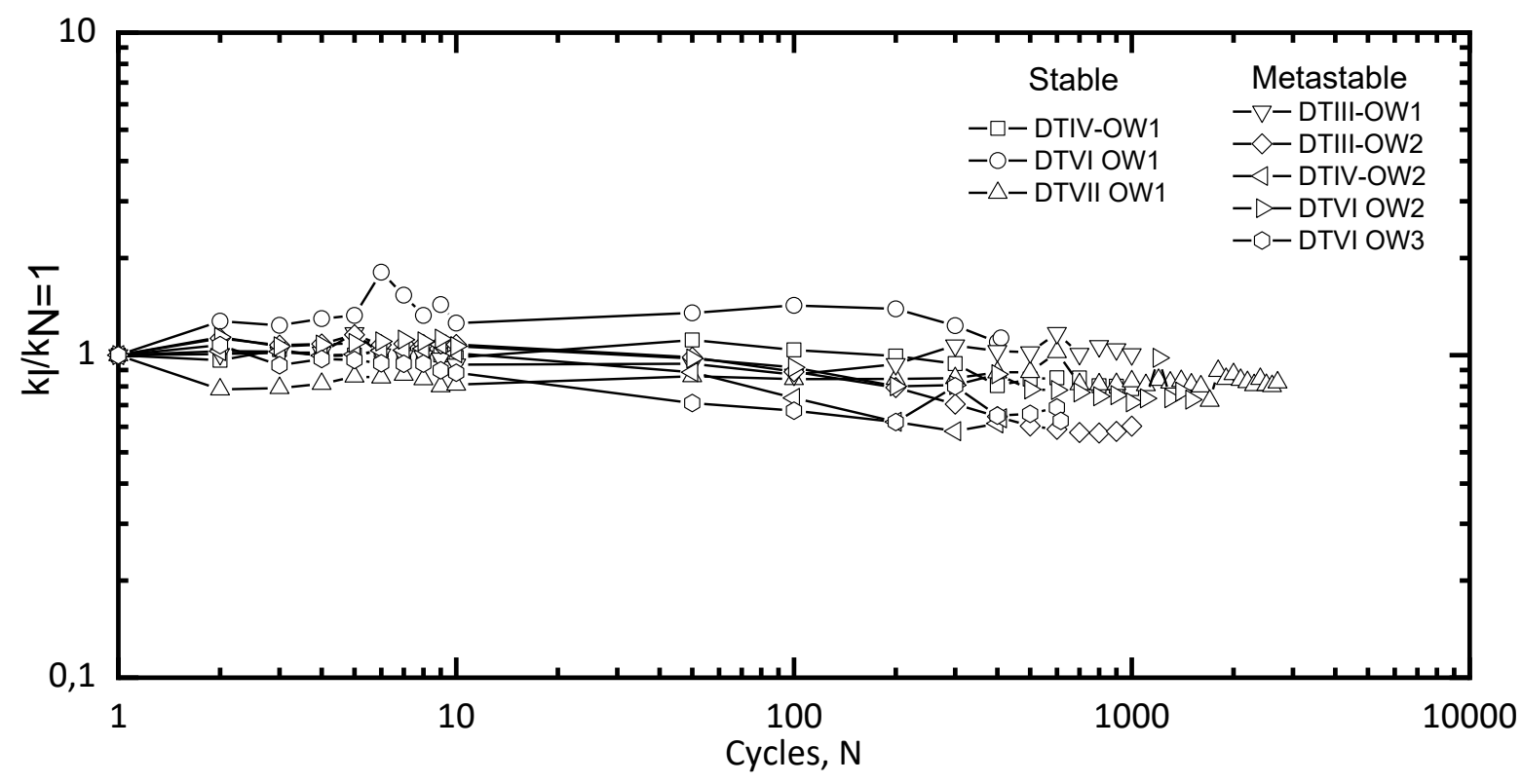

Fig. 15: Normalised axial cyclic pile stiffness versus number of cycles applied in stable and metastable cyclic loading tests for driven piles under BC5 boundary conditions 


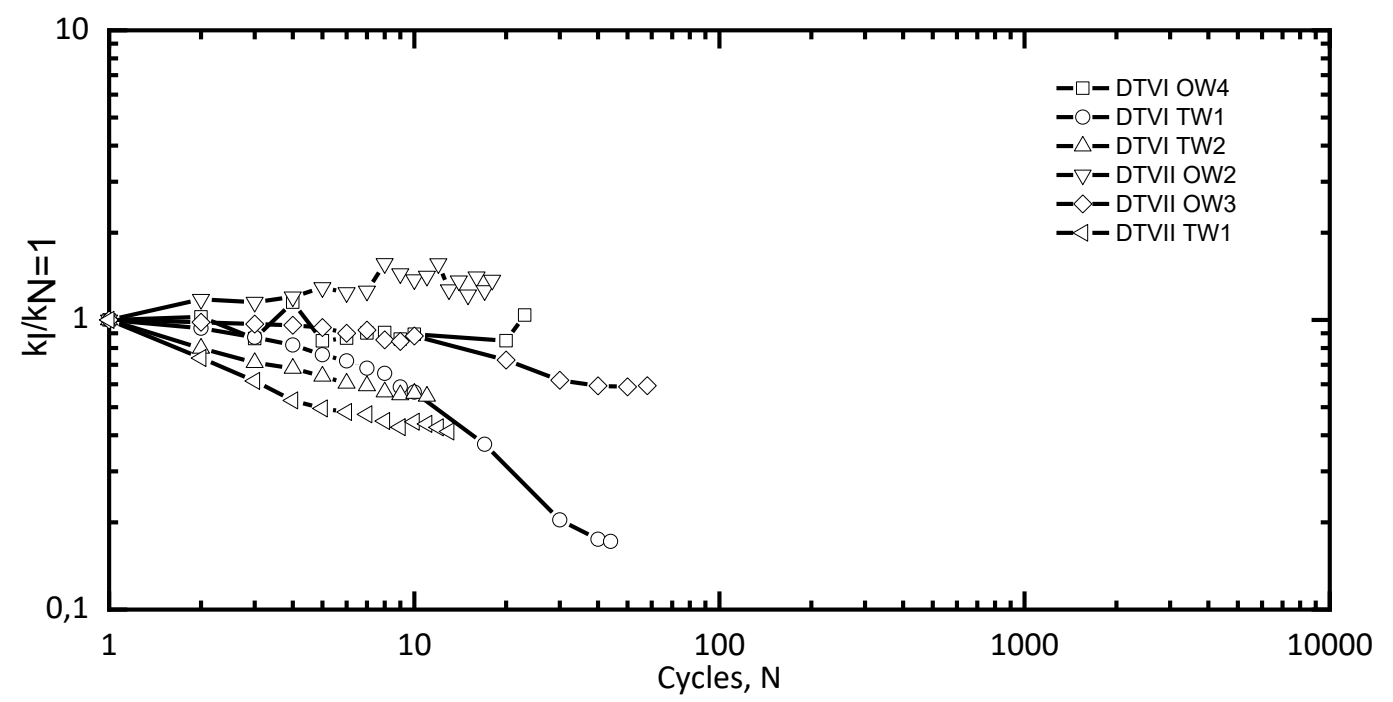

Fig. 16: Normalised axial cyclic pile stiffness versus number of cycles applied for in unstable cyclic loading tests for driven piles tests under BC5 boundary conditions 


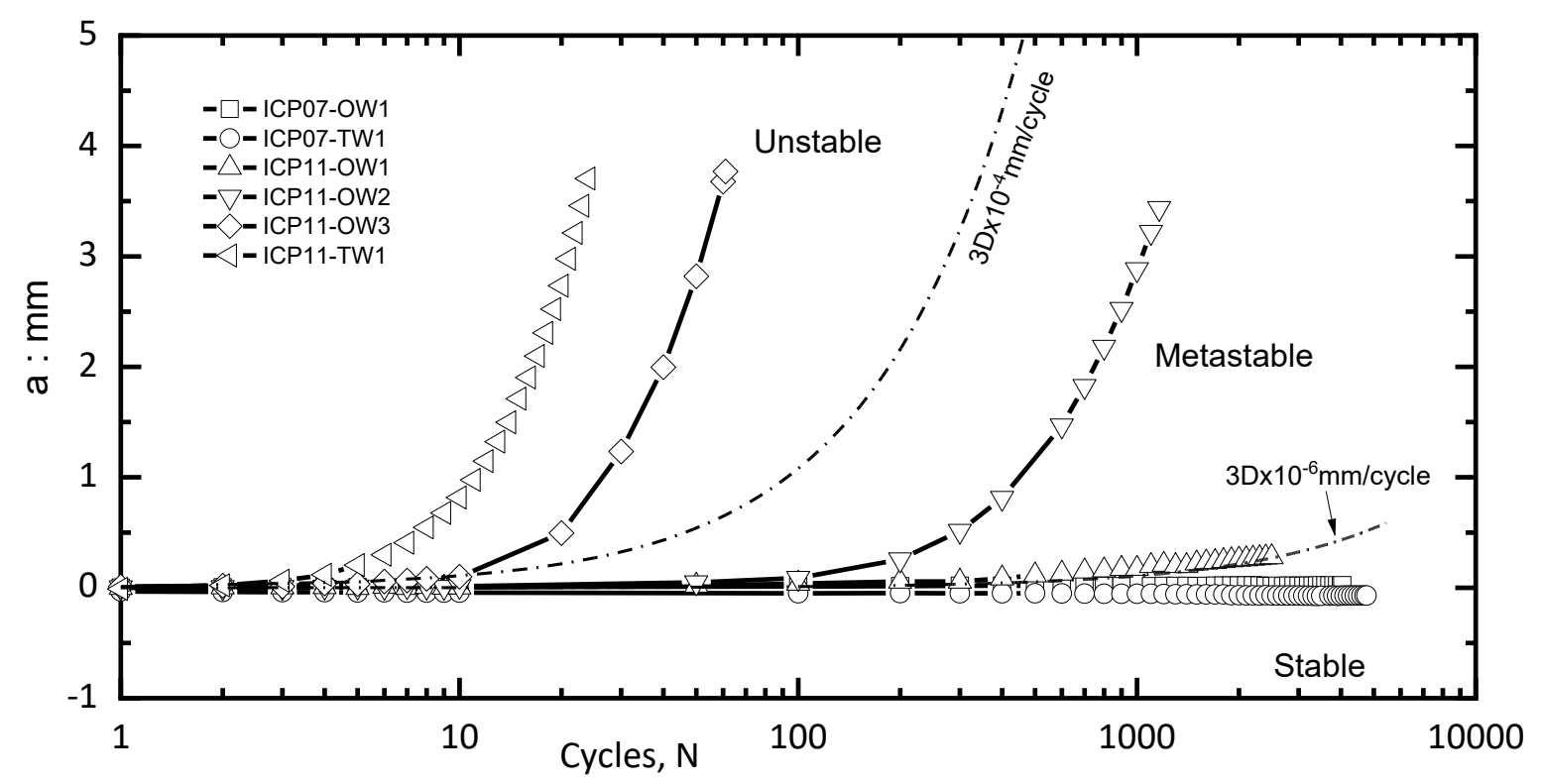

Fig. 17: Permanent accumulated cyclic displacement during cyclic loading tests in dry NE34 sand using the ICP pile under BC5 boundary conditions 


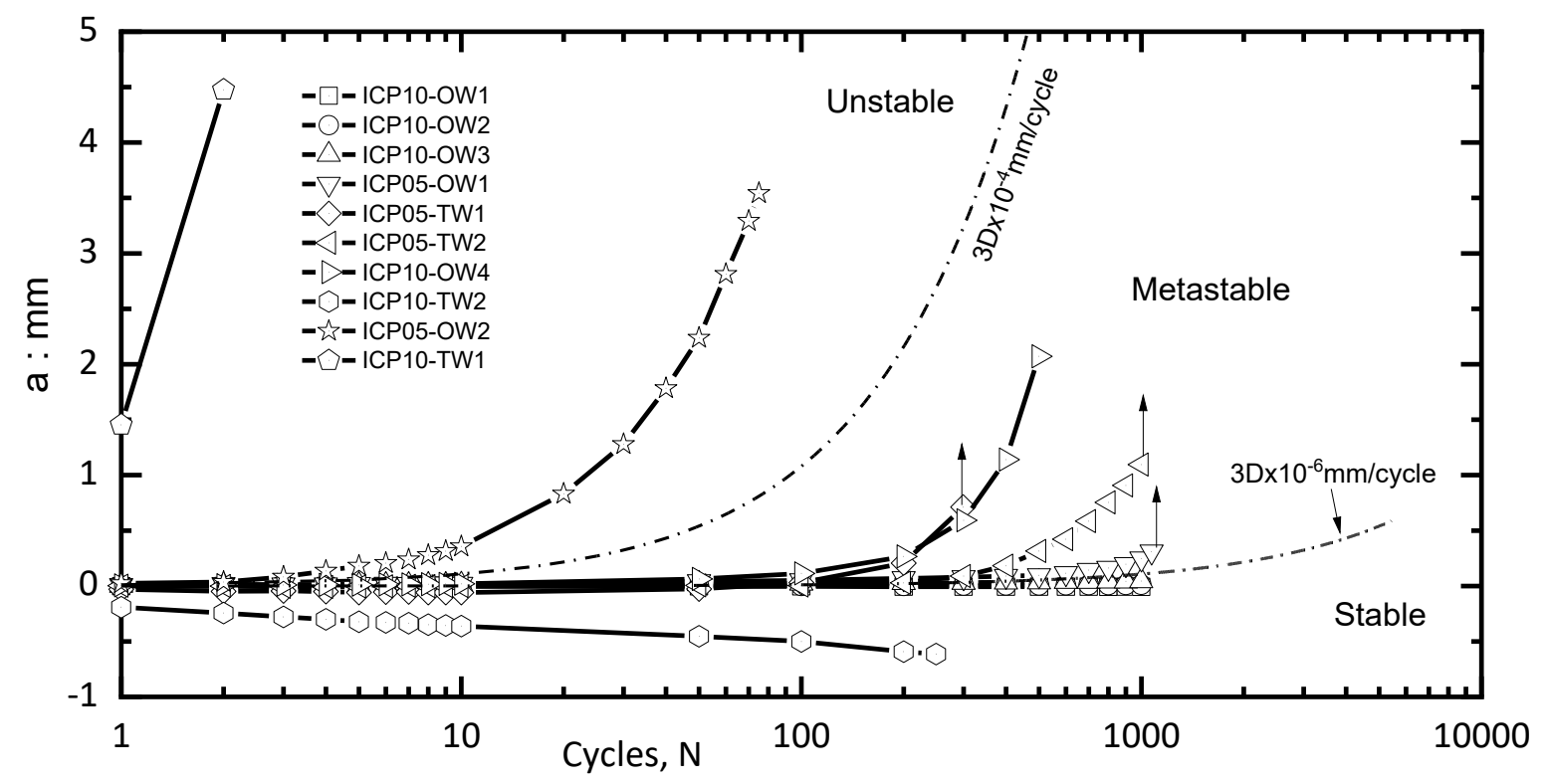

Fig. 18: Permanent accumulated cyclic displacement during cyclic loading tests in dry GA39 sand using the ICP pile under BC5 boundary conditions 


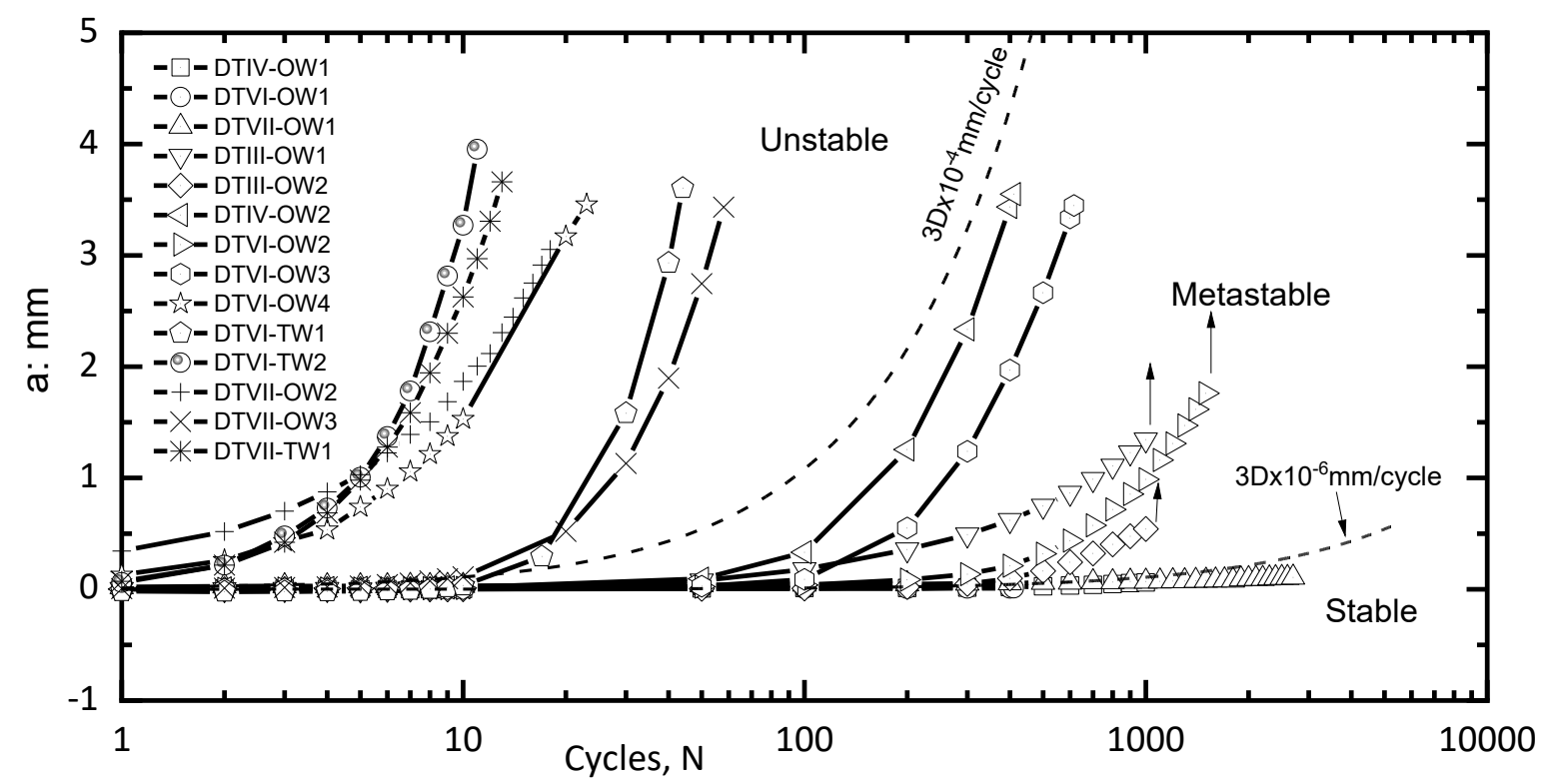

Fig. 19: Permanent accumulated cyclic displacement during stable and metastable cyclic loading tests in dry NE34 sand using driven piles under BC5 boundary conditions 


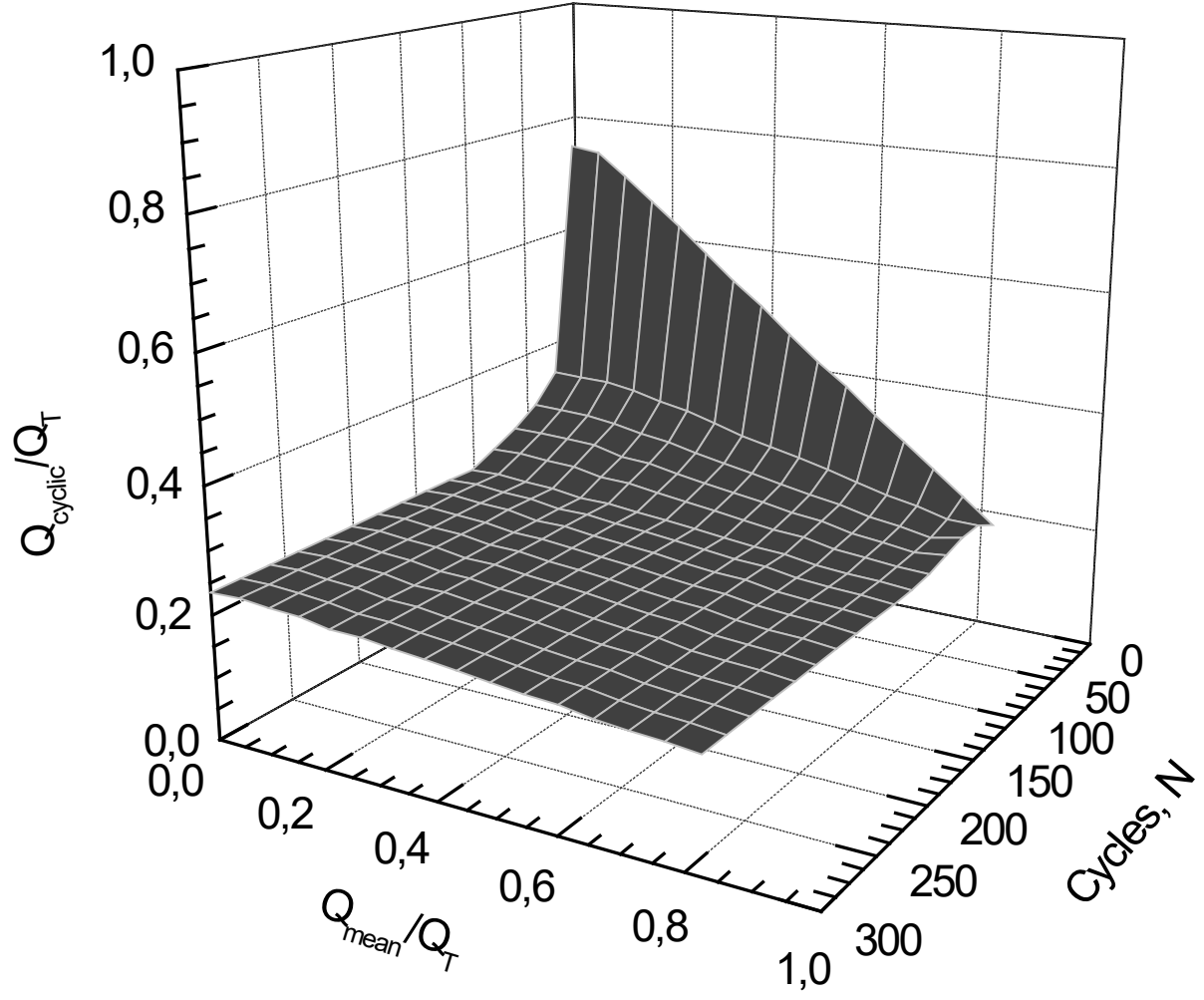

Fig. 20a: 3D plot for permanent accumulated cyclic displacements equivalent to 0.2\%D for Dunkirk field cyclic loading tests, Rimoy et al. 2013. 


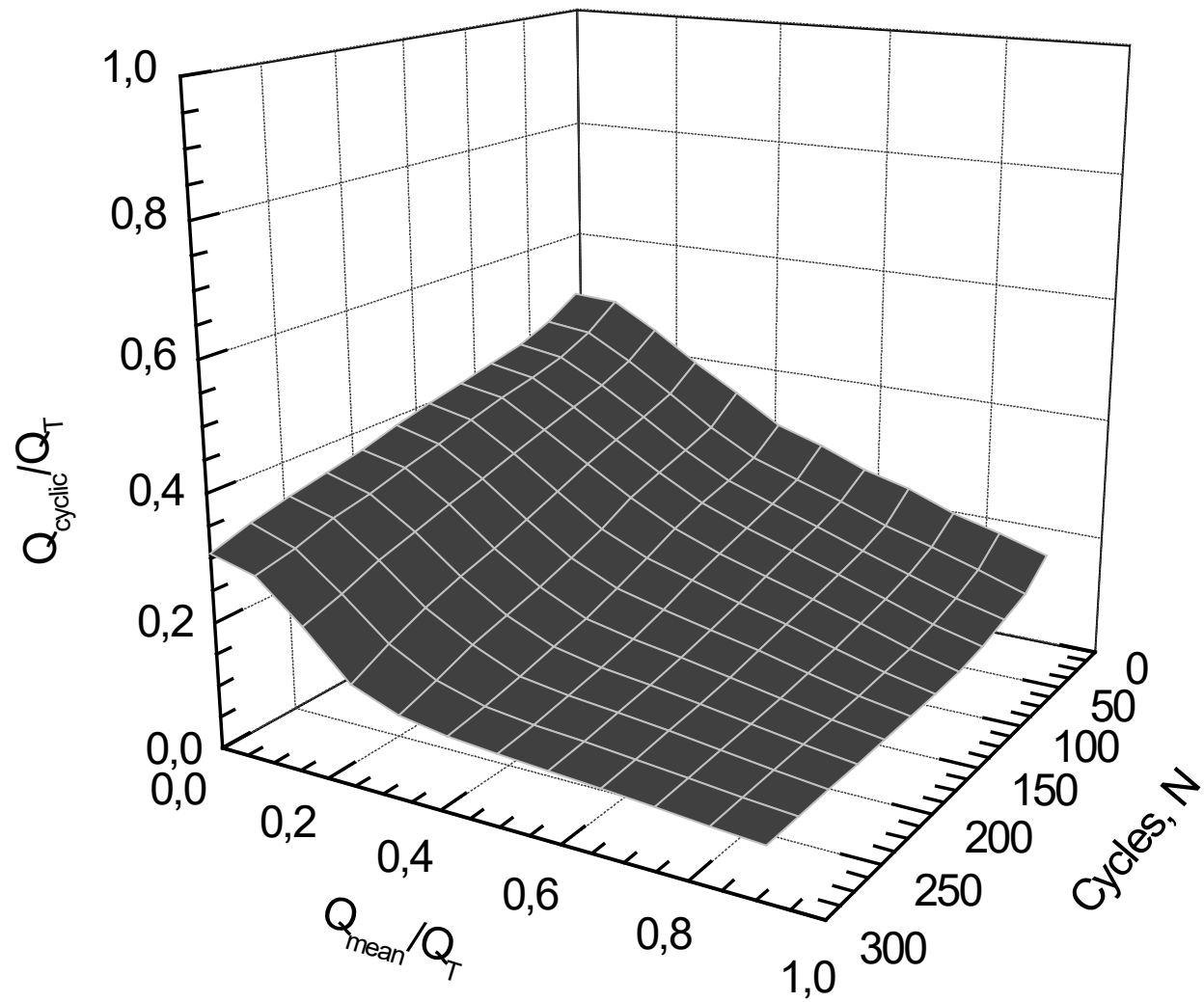

Fig. 20b: 3D plot for permanent accumulated cyclic displacements equivalent to $0.2 \% \mathrm{D}$ for ICP pile tests in dry NE34 sand including data from Tsuha et al. 2012 


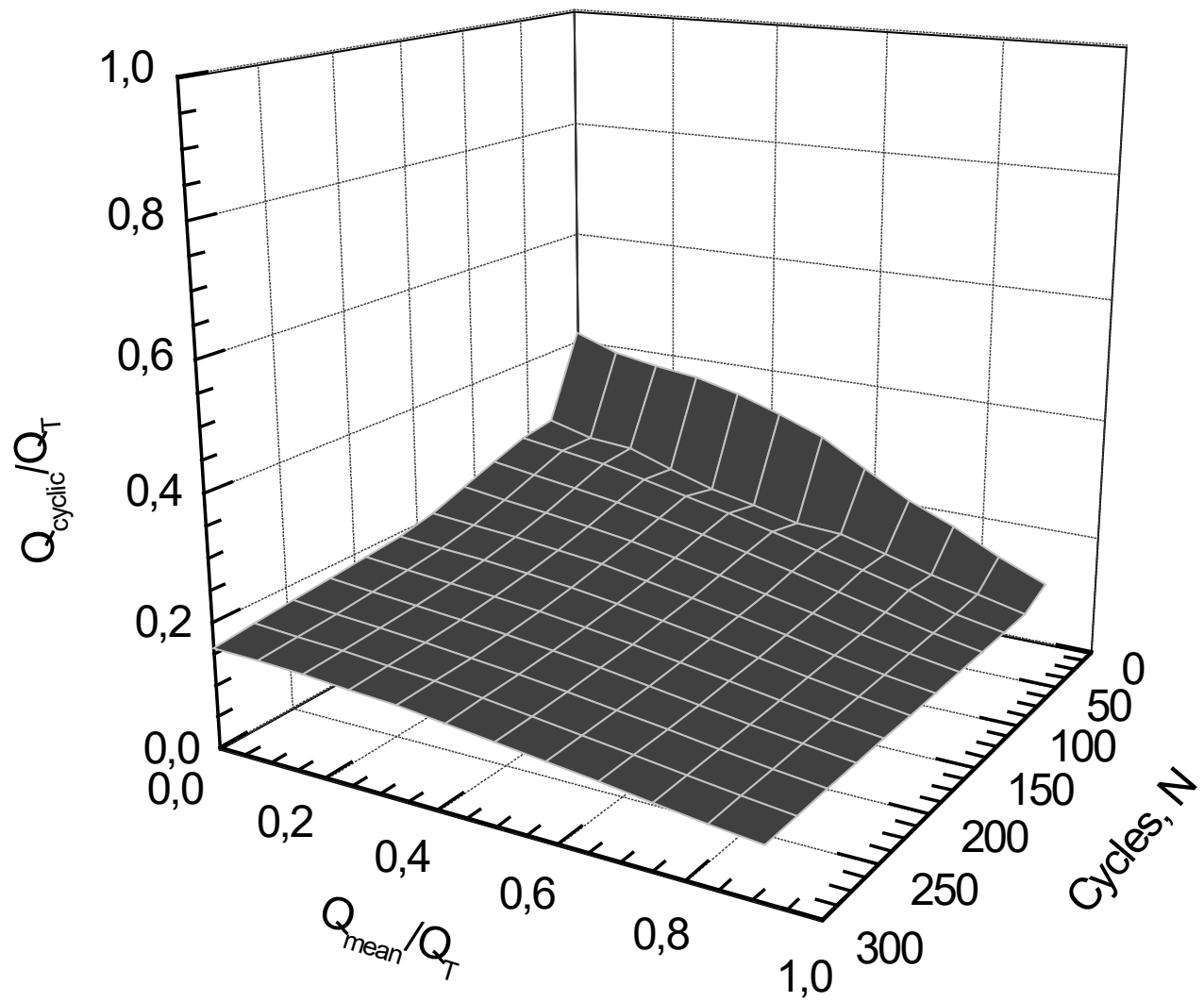

Fig. 20c: 3D plot for permanent accumulated cyclic displacements equivalent to $0.2 \% \mathrm{D}$ for driven pile tests in dry NE34 sand. 


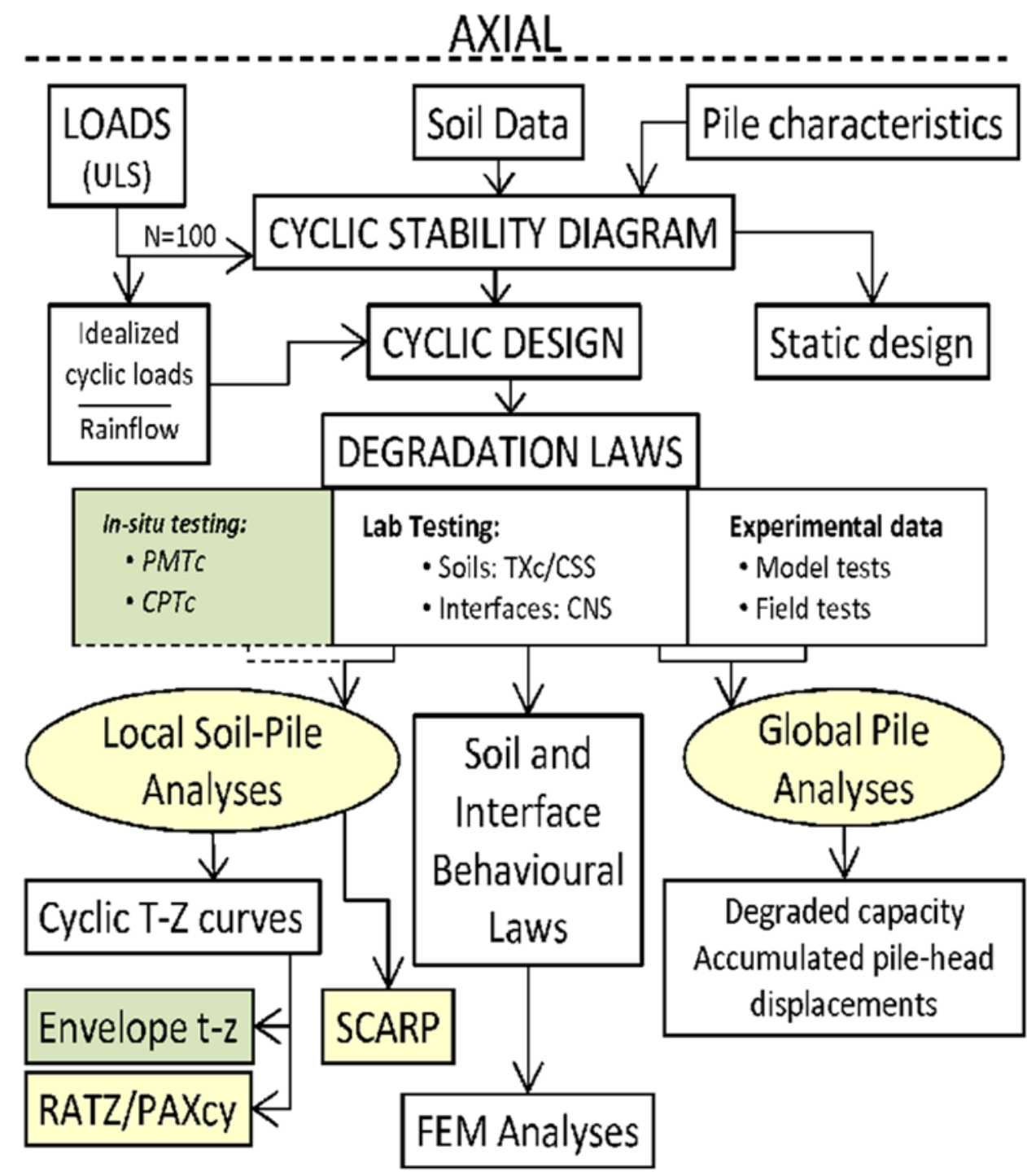

Fig. 21: 'SOLCYP' schematic workflow procedure for assessing pile response to axial cyclic loading; after Jardine et al (2012). 